\title{
Death of Developing Septal Cholinergic Neurons following NGF Withdrawal in vitro: Protection by Protein Synthesis Inhibition
}

\author{
Clive N. Svendsen, a James N. C. Kew, Kristina Staley, and Michael V. Sofroniew \\ Department of Anatomy and MRC Cambridge Centre for Brain Repair, University of Cambridge, Cambridge CB2 3DY, \\ England
}

Fetal septal neurons were grown in vitro under glass coverslips. This sandwich culture method significantly increased general neuronal survival, reduced glial proliferation, and permitted the removal of serum from the growth medium after $5 \mathrm{~d}$ in vitro. Thereafter, a simple, and completely defined, medium was used, and the effects of NGF, NGF withdrawal, and protein synthesis inhibition were examined on septal cholinergic neurons. NGF added to septal cultures at the time of plating resulted in a threefold increase in the number of cholinergic neurons seen at $14 \mathrm{~d}$ in vitro but had no effect on the survival of non-cholinergic cells. Cholinergic neurons identified by staining for AChE, ChAT, and p $75^{\text {NGFr }}$ could be maintained in serum-free, NGF-supplemented medium for over $\mathbf{4 0} \mathrm{d}$. When NGF was removed and NGF antibodies added to 14-d-old cultures, less than $30 \%$ of cholinergic neurons survived a further $4 \mathrm{~d}$, but when NGF was similarly withdrawn from 35 -d-old cultures, over $75 \%$ of cholinergic neurons survived. Reapplication of NGF after 3 but not after 12 or more hours of NGF withdrawal from 14-d-old cultures prevented the death of most cholinergic neurons. When NGF was withdrawn from 14-d-old cultures in the presence of the protein synthesis inhibitor cycloheximide, over $75 \%$ of the cholinergic neurons survived. These findings suggest that septal cholinergic neurons are dependent on NGF for survival only during a critical period of development and that growth factor-regulated developmental cell death may occur in CNS neurons by activation of programmed cell death requiring protein synthesis.

IKey words: NGF, cycloheximide, basal forebrain cholinergic neurons, primary neuronal tissue culture, naturally occurring cell death, apoptosis]

Studies on the PNS suggest that NGF released by target cells regulates the survival and differentiation of developing sympathetic and dorsal root ganglion (DRG) neurons (Levi-Montalcini and Angeletti, 1963). Mature sympathetic neurons appear to remain dependent on NGF for survival (Greene, 1977a;

\footnotetext{
Received Dec. 3, 1992; revised Mar. 30, 1993; accepted June 24, 1993

We thank Ms. S. J. Stevens for technical assistance, Mr. J. Bashford for photography, Dr. E. M. Johnson and Ms. P. A. Osborne for NGF and antibodies to NGF and p $75^{\mathrm{N}(i \pi R}$, Dr. H. Rohrer for antibody to NGF, and Dr. F. Eckenstein for antibody to ChAT. This work was supported by grants from Merck, Sharpe \& Dohme Research Laboratories, the Wellcome Trust, and the Research Corporation Trust to M.V.S., and by studentships from the SERC to C.N.S., the MRC to J.N.C.K., and the Wellcome Trust to K.S.

Correspondence should be addressed to Michael V. Sofroniew, Department of Anatomy, Downing Street, Cambridge CB2 3DY, England.

a Present address: Department of Experimental Psychology, University of Cambridge, England.

Copyright (c) 1994 Society for Neuroscience $0270-6474 / 94 / 140075-13 \$ 05.00 / 0$
}

Gorin and Johnson, 1979), while mature DRG neurons do not (Greene, 1977b; Barde et al., 1980; Schwartz et al., 1982). Within the CNS, cholinergic neurons of the basal forebrain bear lowaffinity (p7 $5^{\mathrm{NGFR}}$ ) and high-affinity (p140 1rk) NGF receptors and retrogradely transport NGF from their target region, the hippocampus (Seiler and Schwab, 1984; Taniuchi el al., 1986; Dawbarn et al., 1988; Mufson et al., 1989; Holtzman et al., 1992), but the role of NGF regarding these neurons is not well understood.

Addition of NGF to tissue cultures of basal forebrain cells (Hartikka and Hefti, 1988), and intraventricular infusion of NGF to neonatal and adult rats (Gnahn et al., 1983; Mobley et al., 1986), increases the size and ChAT activity of basal forebrain cholinergic neurons, indicating that NGF can regulate the chemical and structural phenotype of these neurons both in vitro and in vivo. Studies assessing the effects of NGF on the survival of basal forebrain cholinergic neurons show that NGF increases the number of developing cholinergic neurons in low-density but not high-density septal cultures (Hartikka and Hefti, 1988; Alderson et al., 1990), and that pharmacologic doses of NGF prevent the disappearance of septal cholinergic neurons after fimbria-fornix lesions in the adult rat (Hefti, 1986; Williams et al., 1986; Kromer, 1987), suggesting that NGF might be an obligatory survival factor for these neurons throughout life. However, infusions of NGF antibody into the ventricles of neonatal rats appear not to cause the death of basal forebrain cholinergic neurons (Gnahn et al., 1983; Vantini et al., 1989), and adult septal cholinergic neurons survive following excitotoxic lesions that deplete the hippocampus of NGF mRNA (Sofroniew et al., 1990, 1993). Thus, the degree to which NGF regulates the survival of basal forebrain cholinergic neurons during development or in the adult is uncertain.

In this study we examined whether septal cholinergic neurons grown in tissue culture in the presence of NGF are dependent on NGF for survival at different stages of maturity. Since dissociated cultures of fetal septal cells undergo massive degeneration over the first $7 \mathrm{~d}$ in vitro and are difficult to maintain for long periods of time in serum-free conditions (Hartikka and Hefti, 1988; Alderson et al., 1990), we adapted a sandwich culture method previously shown to increase the short- and long-term survival of hippocampal neurons in vitro (Brewer and Cotman, 1989). Using this method we examined the reaction of septal cholinergic neurons, maintained in the presence of $\mathrm{NGF}$, to NGF withdrawal at 14 or $35 \mathrm{~d}$ in vitro. In addition, we investigated whether the cell death observed following NGF withdrawal from septal cholinergic neurons after $14 \mathrm{~d}$ in vitro could be prevented by inhibition of protein synthesis as previously described for developing peripheral neurons (Martin et al., 1988; Edwards et al., 1991). 


\section{Materials and Methods}

Basal forebrain cultures. Brains were removed from Wistar rat fetuses harvested at embryonic day 16 (E16) and immersed in Hanks balanced salt solution (HBSS; Sigma) without calcium and magnesium. A longitudinal cut was made in the cortex, exposing the underlying subcortical structures, and the septum, distinguished by its mediorostral position and its characteristic oval shape, was carefully dissected out whole from each side of the brain (Hefti et al., 1989). After removing meningial tissues, 12 pairs of septa were transferred into $0.1 \%$ trypsin and incubated at $37^{\circ} \mathrm{C}$ for $25 \mathrm{~min}$. Following three $7 \mathrm{~min}$ washes in $5 \mathrm{ml}$ of HBSS with calcium and magnesium, the septa were gently triturated in $1.2 \mathrm{ml}$ of HBSS using a glass pipette with a narrow polished tip. Various volumes of the resulting cell suspension were added to $1 \mathrm{ml}$ of $\mathrm{CO}_{2}$ equilibrated Dulbecco's modified Eagle's medium (DMEM; Imperial Labs) supplemented with $100 \mathrm{~mm}$ glutamine, $1 \mu \mathrm{l} / \mathrm{ml}$ antibiotic/antimyotic (Sigma), and 10\% fetal calf serum (FCS; Imperial Labs) in 24 multiwell dishes (NUNC, GIBCO). The dishes were then placed in a $37^{\circ} \mathrm{C}$ humidified, $\mathrm{CO}_{2}$-controlled $(5 \%)$ incubator and the cells allowed to fall to rest over a $15 \mathrm{~min}$ period and settle onto either glass coverslips or the plastic bottom of the well coated with poly-L-lysine $(1 \mathrm{mg} / \mathrm{ml}$; Sigma). Using 12 septa in a final trituration volume of $1.2 \mathrm{ml}$ and adding $50 \mu \mathrm{l}$ of the resulting cell suspension to $1 \mathrm{ml}$ of medium gave a final plating cell density of approxinnately $50,000 \mathrm{cells} / \mathrm{cm}^{2}$. Once cells had attached to either the glass coverslips or bottoms of the plastic wells, three different methods were compared for long-term maintenance of the cultures. Cultures plated onto glass coverslips either were left openfaced or, $1 \mathrm{hr}$ after plating, coverslips were gently lifted and inverted, leaving the neurons sandwiched between the plastic of the NUNC dish and the poly-L-lysine. Cultures plated directly onto plastic either were left open-faced, or $1 \mathrm{hr}$ after plating, were covered with a glass coverslip to form the sandwich culture. A comparison of plating onto glass or plastic revealed that glass coverslips did not sustain neuronal survival as well as the plastic bottom of the NUNC well. Therefore, after a number of initial experiments, all further studies used cultures plated directly onto the bottom of plastic dishes with a glass coverslip on top to form a sandwich culture. At $5 \mathrm{~d}$ in vitro, all cultures were washed with an identical growth medium but lacking FCS. This completely defined medium (DMEM supplemented only with glutamine and antibiotic) was exchanged for fresh, similar medium every $7 \mathrm{~d}$. For different experiments, NGF (100 ng/ml; Dr. E. M. Johnson, Washington University, St. Louis), NGF antibodies $(0.2 \%$ goat polyclonal anti-NGF, lot 55-050190, Dr. E. M. Johnson; or $30 \mu \mathrm{g} / \mathrm{ml}$ mouse monoclonal antiNGF, Dr. H. Rohrer, Rohrer et al., 1988), or cycloheximide (0.01-1.0 $\mu \mathrm{g} / \mathrm{ml}$; Sigma) was added to this medium

Dorsal root ganglion cultures. Primary dissociated cultures of rat sensory neurons were prepared from E16-E 17 Wistar rat fetuses. Between 100 and 150 DRGs were dissected from eight embryos, placed in HBSS, and dispersed by trypsinization and trituration as described above; 40 $\mathrm{ml}$ of the resulting suspension was pipetted onto dry coverslips coated with collagen $(1 \mathrm{mg} / \mathrm{ml}$; Sigma) and placed in 24-well, $16 \mathrm{~mm}$ NUNC dishes. After $60 \mathrm{~min}$ in a humidified, $\mathrm{CO}_{2}$-controlled (5\%) incubator, $500 \mathrm{ml}$ of DMEM supplemented with glutamine, antibiotics, and $10 \%$ FCS was added to each well. Some cultures were left open-faced while others were inverted, in both cases in the presence or absence of $\mathrm{NGF}$ $(100 \mathrm{ng} / \mathrm{ml})$. After $48 \mathrm{hr}$ in the $37^{\circ} \mathrm{C}, \mathrm{CO}_{2}$-controlled incubator, the cultures were fixed and stained for cytological analysis.

Immunocytochemistry. When cultures were harvested for fixation, coverslips were gently rotated and removed. Without this step some neurons were washed off due to the suction effect of raising the coverslip. Cultures were fixed in $4 \%$ paraformaldehyde for $45 \mathrm{~min}$, washed three times in Tris buffer with azide (pH 7.8), and left overnight in primary antibody to either glial fibrillary acidic protein (GFAP; 1:2700; DAKO), neuron-specific enolase (NSE; $1: 2000 ; \mathrm{DAKO}$ ), choline acetyltransferase (ChAT; 1:12; Dr. F. Eckenstein, Oregon Health Sciences University), or low-dfinily NGF receptor (p75 NGFr $1.5 \mu \mathrm{g} / \mathrm{m}$ MC-192; Dr. E. M. Johnson) in Triton/carrageenan solution. Following three 15 min washes in Tris with azide, the cultures were incubated for $1 \mathrm{hr}$ in the appropriate second antibody: anti-rat $\lg (j$ for $\mathrm{ChAT}(1: 40$; Sigma), biotinylated antimouse IgG for p75 NGFR $(1: 200$; Vector Labs), and biotinylated antirabbit IgG for NSE and GFAP (1:200; Vector Labs). Cultures processed for ChAT were then incubated for another hour in rat peroxidaseantiperoxidase (1:40; Sera Labs) and cultures processed for $\mathrm{p} 75^{\mathrm{NGFR}}$, GFAP, and NSE were stained via addition of avidin and biotinylated peroxidase complex (Vector Labs). All staining was developed by exposure to a diaminobenzidine $(2 \mathrm{mg} / \mathrm{ml}$; Sigma $), \mathrm{H}_{2} \mathrm{O}_{2}(5 \mathrm{ml} / 10 \mathrm{ml})$ mixture for $10 \mathrm{~min}$ before being washed in Tris buffer with azide. Cultures grown on glass coverslips were dehydrated, cleared in xylene, and mounted onto glass slides using DePex mounting medium. Cultures grown on the surface of the NUNC cultures dishes were washed in Tris buffer with azide and mounted in five drops of heated $\left(48^{\circ} \mathrm{C}\right)$ liquid gelatin, which then solidifed on cooling.

$A C h E$ histochemistry and cytology. Cultures were fixed in 4\% paraformaldehyde for $25 \mathrm{~min}$, washed three times in $0.1 \mathrm{M}$ sodium acetate, and incubated in $50 \mathrm{~mm}$ acetate buffer (pH 6.0) containing $5 \mathrm{~mm}$ sodium citrate, $3 \mathrm{~mm}$ cupric sulfate, $10 \mathrm{~mm}$ potassium ferricyanide, and $4 \mathrm{~mm}$ acetylthiocholine iodide for $1 \mathrm{hr}$. Cultures were then washed once in acetate buffer $(0.1 \mathrm{M})$, exposed to $1 \%$ ammonium sulfate for $1 \mathrm{~min}$, washed again in acetate buffer followed by nitrate buffer $(0.1 \mathrm{M})$, and developed in $0.1 \%$ silver nitrate for $1 \mathrm{~min}$. For general cytological staining, luxol fast blue (LFB) at $0.1 \%$ in $70 \%$ alcohol was added for $30 \mathrm{~min}$ to cultures previously stained for $\mathrm{AChE}$, or to unstained cultures fixed in $4 \%$ paraformaldehyde and partially dehydrated in $50 \%$ alcohol. Cultures were then rinsed twice in $100 \%$ alcohol, cleared and mounted in DePex (cultures grown on glass coverslips), or rinsed in water and mounted in gelatin (cultures grown in NUNC wells).

Quantitative analysis. Total neuronal counts and cell size measurements were performed using a semiautomatic, interactive, computerized image analysis system (Seescan, Cambridge). For cell counts, a video inlage with a final field size of $220 \mu \mathrm{m} \times 300 \mu \mathrm{m}$ was obtained using a $25 \times$ objective. Viable neurons were identified on the basis of having a phase-bright cell body with at least two visible processes. Cholinergic neurons were counted as $\mathrm{AChE}, \mathrm{p} 75^{\mathrm{NGFR}}$, or ChAT positive when over $50 \%$ of the cell body was positively stained. In LFB stained cultures, neurons and astrocytes could be differentiated on the basis of cell morphology as compared with neurons and astrocytes identified by immunohistochemical labeling with, respectively, NSE or GFAP (see Fig. 3). The number of cholinergic or non-cholinergic neurons was counted in five random adjacent fields located in the outer $3-4 \mathrm{~mm}$ of the cultures and the average number extrapolated to give a total number of neurons per $\mathrm{cm}^{2}$. Dead or degenerating neurons were identified by severe shrinkage of the cell body and absence of processes (see Fig. 5) and were not counted. The very center of cultures were avoided for cell counts because after $21 \mathrm{~d}$ in vitro variable amounts of necrosis and cell death were noted in the center of sandwich as reported also by Brewer and Cotman (1989) using hippocampal cells. All values are expressed as the mean \pm standard error of four to six sister wells per experimental group for each experiment. All experiments described were repeated at least twice with the same results. For cross-sectional area measurements, individual fields were captured using a $40 \times$ objective, digitally filtered and thresholded manually based on regions of greatest optical density. The first 20 AChF-positive neurons encountered in randomly selected fields in each of six culture wells per experimental group were measured and values expressed as the mean of the means for the group.

\section{Results}

Effects of the sandwich technique and NGF on short-term general neuronal survival in septal and DRG cultures

Initial studies were aimed at characterizing the effects of the sandwich culture technique of Brewer and Cotman (1989) on septal cells. In agreement with their findings, neuronal survival was substantially higher during the first $3 \mathrm{~d}$ in vitro in sandwich cultures in serum-supplemented medium, particularly at low cell densities (Figs. $1 ; 2 A, C$ ). A plating density of 150,000 cells/ $\mathrm{cm}^{2}$ was selected for subsequent studies using longer survival times and removal of serum from the medium at $5 \mathrm{~d}$ in vitro.

After 7 or $14 \mathrm{~d}$ in vitro only $20 \%$ or $1 \%$, respectively, of cells plated at a density of 150,000 cells $/ \mathrm{cm}^{2}$ in open-faced septal cultures in the absence of exogenous NGF remained alive as neurons, and these were growing on top of a rapidly forming glial monolayer (Fig. $3 B, D, F$; Table 1). In contrast, at these same time points over $90 \%$ and $40 \%$ of cells survived as neurons in sister sandwich cultures, and glial cells were few in number and well differentiated (Fig. 3A,C,E; Table 1). The morphological appearance of neurons and glia in LFB-stained cultures (Fig. $3 A, B$ ) was confirmed by immunohistochemical staining for, respectively, NSE (Fig. $3 E, F$ ) and GFAP (Fig. $3 C, D$ ). There was 


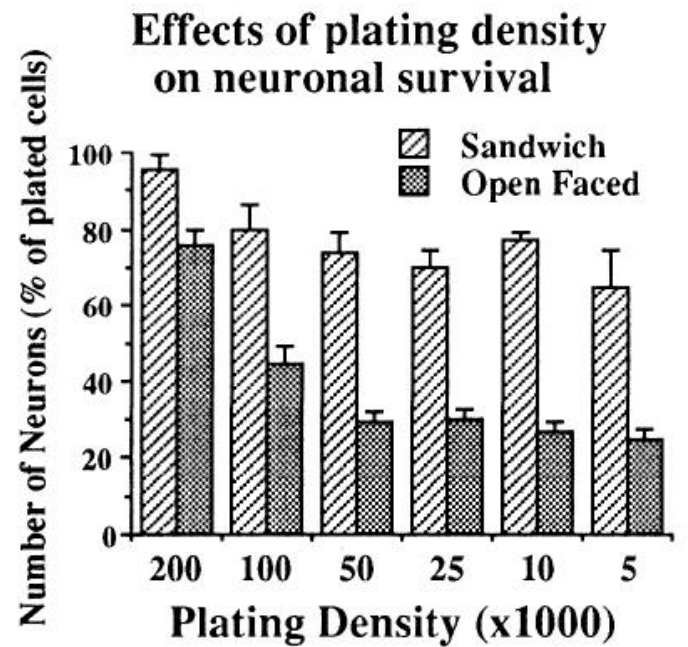

Figure 1. Graph comparing the effects of plating density on general neuronal survival in either open-faced or sandwich sister septal cultures grown in the absence of exogenous NGF. After $3 \mathrm{~d}$ in vitro, cultures were harvested, and the number of LFB-stained neurons counted in five fields per culture well. Neuronal counts are expressed as a percentage of the number of plated cells (i.e., number of counted neurons/number of plated cells $\times 100$ ). $N=4$ or 6 culture wells per data point $( \pm$ SEM) from a typical experiment. This experiment was conducted two times with similar results. no increase in general neuronal survival when NGF $(100 \mathrm{ng} /$ $\mathrm{ml}$ ) was added at the time of plating to either open-faced or sandwich cultures for 3, 7, or $14 \mathrm{~d}$ (Fig. 2, Table 1).

DRG cultures were used to compare the effects of the sandwich culture technique and NGF on a population of neurons known to be dependent on NGF for survival (Johnson et al., 1980). In open-faced DRG cultures plated at 200,000 cells $/ \mathrm{cm}^{2}$ and grown in serum-supplemented medium for $3 \mathrm{~d}$ in the absence of exogenous NGF, less than $5 \%$ of initial population of plated cells survived as neurons $\left(8095 \pm 5938\right.$ neurons $\left./ \mathrm{cm}^{2}\right)$. In sister sandwich cultures grown under similar conditions there were essentially no viable neurons at $3 \mathrm{~d}$ in vitro. Addition of NGF $(100 \mathrm{ng} / \mathrm{ml})$ to the medium at the time of plating sustained large numbers of neurons in open-faced $(175,194 \pm 27,148$ neurons $/ \mathrm{cm}^{2}$ ) cultures and substantially improved neuronal survival in sandwich cultures $\left(69,993 \pm 15,695\right.$ neurons $\left./ \mathrm{cm}^{2}\right)$.

\section{Effects of NGF on cholinergic neurons in maturing sandwich septal cultures}

Initial studies used $\mathrm{AChE}$ histochemistry to identify presumptive cholinergic neurons (Eckenstein and Sofroniew, 1983) in septal cultures. In the absence of exogenous NGF, a small number of AChE-positive neurons were present in sandwich septal cultures at $7 \mathrm{~d}$ and this number had declined by half at $14 \mathrm{~d}$ (Table 2), but a few AChE-positive neurons persisted under these conditions for at least $35 \mathrm{~d}$. Addition of NGF (100 ng/
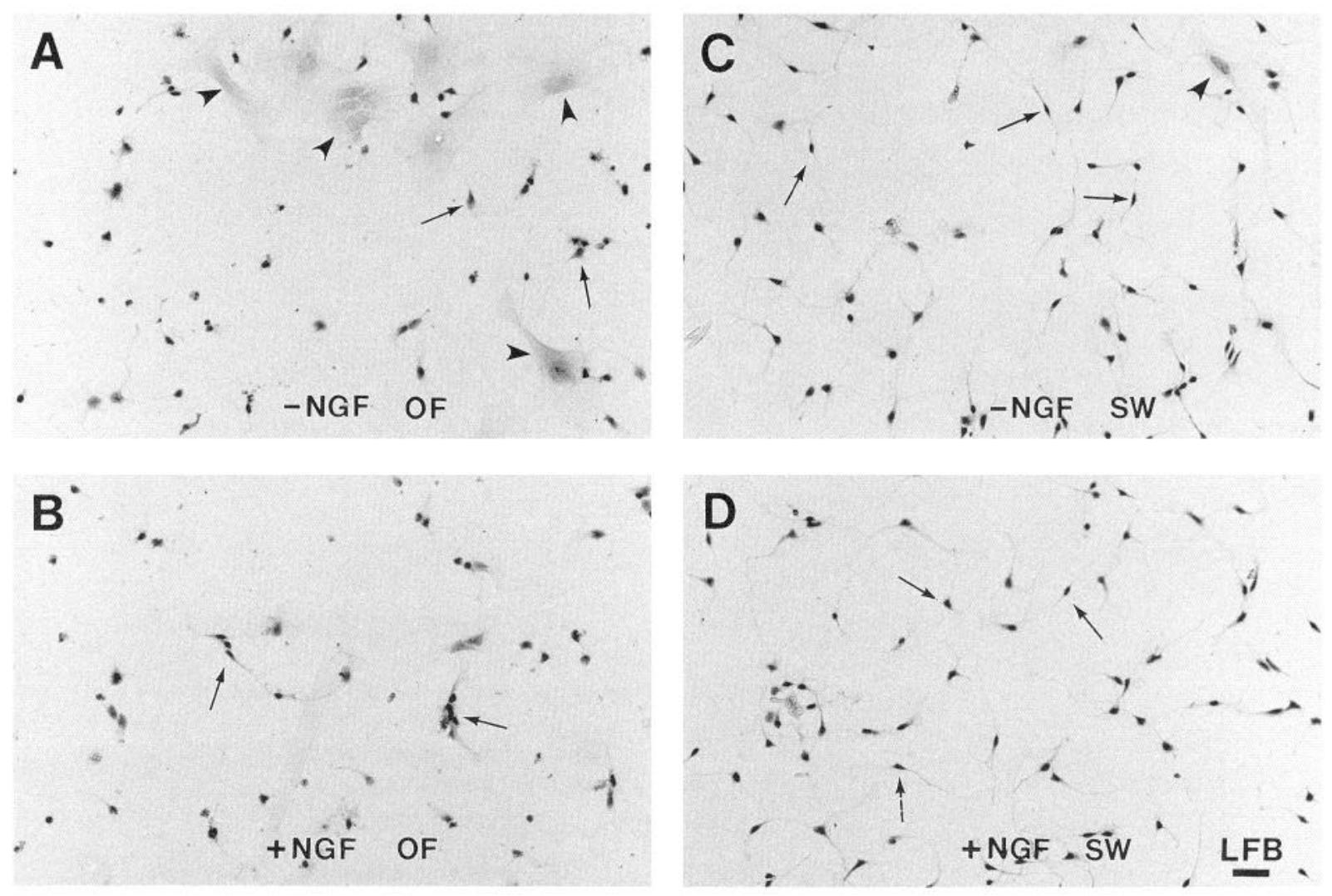

Figure 2. Photomicrographs showing the effects of the sandwich culture technique and NGF treatment on short-term general neuronal survival in septal cultures at $3 \mathrm{~d}$ in vitro. Cultures were stained with LFB. In open-faced $(O F)$ septal cultures $(A)$ very few neurons (arrows) survived and there were many dividing astrocytes (arrowheads). The sandwich $(S W)$ culture technique $(C)$ significantly increased neuronal (arrows) survival and reduced astrocytic (arrowhead) proliferation. Addition of NGF $(100 \mathrm{ng} / \mathrm{ml})$ to the medium at the time of plating did not increase general neuronal survival or affect the number of astrocytes in either open-faced $(B)$ or sandwich $(D)$ cultures. Scale bar, $150 \mu \mathrm{m}$. 

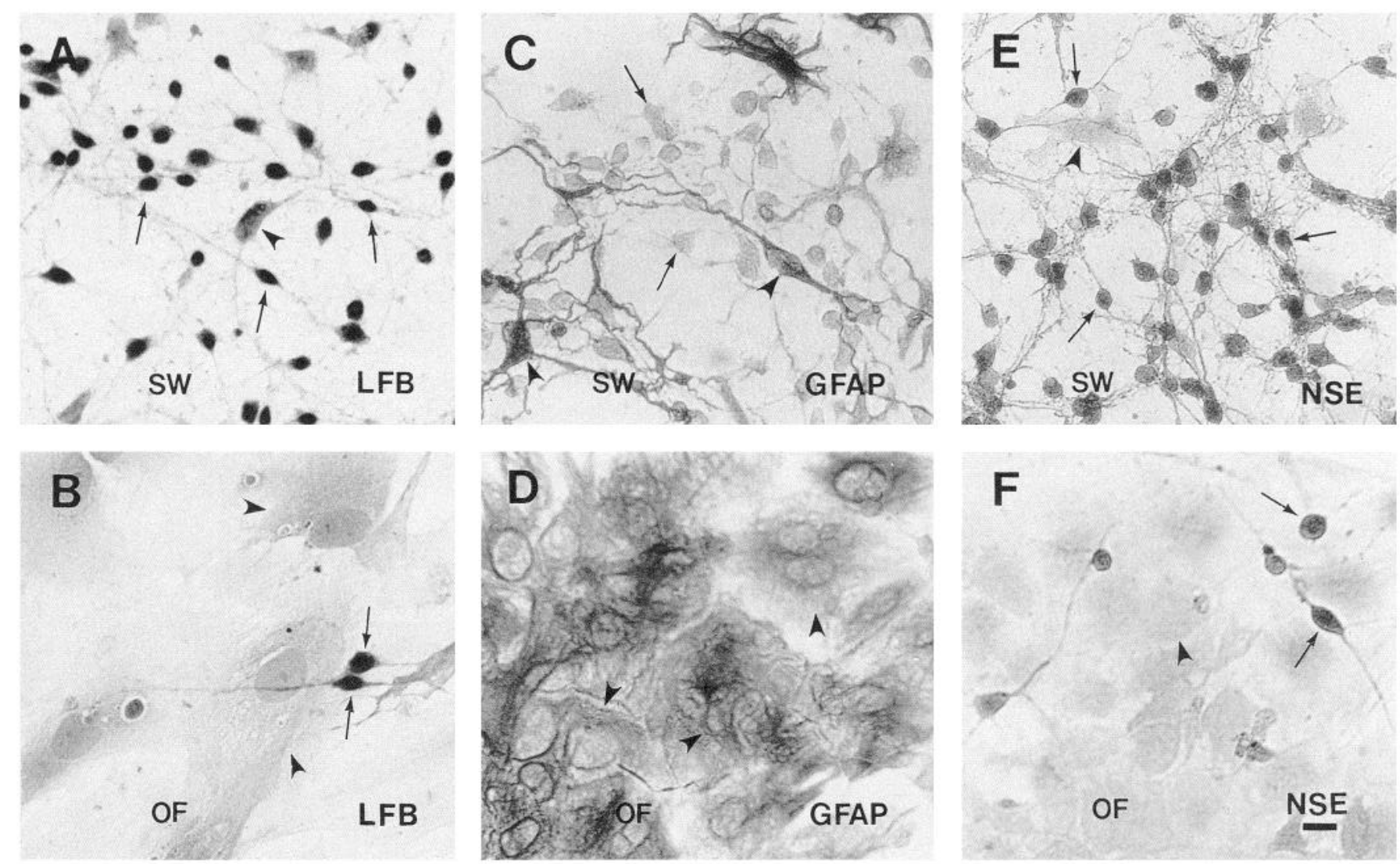

Figure 3. Photomicrographs comparing the density of neurons and glial cells in sister sandwich $(S W)(A, C, E)$ and open-faced $(O F)(B, D, F)$ septal cultures at $7 \mathrm{~d}$ in vitro after plating at a density of 150,000 cells $/ \mathrm{cm}^{2}$. Cells are stained either with LFB $(A, B)$ or immunohistochemically for GFAP $(C, D)$ or NSE $(E, F)$. Large, GFAP-positive, NSE-negative cells that appear lightly stained with LFB were considered astrocytes (arrowheads). Small, NSE-positive, GFAP-negative cells that appear darkly stained with LFB were considered neurons (arrows). Note the small number of neurons and confluent mat of glial cells in the open-faced cultures $(B, D, F)$ and the large number of neurons and small number of well differentiated astrocytes in the sandwich cultures $(A, C, E)$. Scale bar, $30 \mu \mathrm{m}$.

$\mathrm{ml}$ ) to sandwich cultures at the time of plating significantly increased the staining intensity, size, and number of AChEpositive presumptive cholinergic neurons detectable at 7 and $14 \mathrm{~d}$ in vitro (Table 2). In the continuous presence of NGF, the number of cholinergic neurons remained approximately the same for at least $35 \mathrm{~d}$ ( 992 cholinergic neurons $/ \mathrm{cm}^{2}$ at $35 \mathrm{~d}$ ) (Fig. 4). NGF-supplemented cholinergic neurons matured slowly in vitro, increasing in size particularly between 7 and $21 \mathrm{~d}$ (Fig. 4, Table 2) and gradually elaborating a dense network of AChE-positive fibers (Fig. 4). In contrast, the number of non-cholinergic neurons decreased from nearly $90 \%$ of the plating density $(140,000$

Table 1. Effects of NGF and the sandwich culture method on general neuronal survival at 7 and $14 \mathrm{~d}$ in vitro

\begin{tabular}{llccr} 
& Treat- & \multicolumn{2}{c}{ Number of surviving neurons } \\
\cline { 3 - 5 } & ment & $7 \mathrm{~d}$ in vitro & $14 \mathrm{~d}$ in vitro \\
\hline Open-faced culture & $+\mathrm{NGF}$ & $32,352 \pm 3921$ & $1470 \pm$ & 356 \\
& $-\mathrm{NGF}$ & $34,313 \pm 2156$ & $1294 \pm$ & 221 \\
Sandwich culture & $+\mathrm{NGF}$ & $151,960 \pm 7058$ & $62,745 \pm 5882$ \\
& $-\mathrm{NGF}$ & $144,117 \pm 7843$ & $58,823 \pm 7647$
\end{tabular}

All values represent mean number of neurons $/ \mathrm{cm}^{2} \pm$ SEM $(n=6$ cultures per group) from a typical experiment using a plating density of approximately 150,000 cells $/ \mathrm{cm}^{2}$. non-cholinergic neurons $/ \mathrm{cm}^{2}$ at $7 \mathrm{~d}$ ) to about $10 \%$ over this time period (15,625 non-cholinergic neurons/ $\mathrm{cm}^{2}$ at $35 \mathrm{~d}$ ) (Fig. 4).

AChE-positive presumptive cholinergic neurons were further characterized by immunohistochemical staining for ChAT and p $75^{\text {NGFR }}$. In the absence of exogenous NGF, no ChAT-positive but some p75 $5^{\text {NGFr }}$-positive neurons could be detected at $14 \mathrm{~d}$ in vitro (Table 2). With addition of NGF to the medium from plating, both ChAT- and p $75^{\text {NGFR }}$-positive neurons were detectable at $14 \mathrm{~d}$ in vitro and were similar in number, size, and appearance to AChE-positive neurons in sister wells (Fig. 5, Table 2). ChAT- and p $75^{\text {NGFR }}$-stained neurons matured with time in the presence of NGF in a manner similar to AChEpositive neurons and were present in about equal numbers for at least $35 \mathrm{~d}$. Delayed addition of NGF for $7 \mathrm{~d}$ starting at $14 \mathrm{~d}$ in vitro did not significantly increase the number of $\mathrm{AChE}$ - or p $75^{\text {NGFR }}$-stained neurons, but did significantly increase the number of ChAT-stained neurons, as compared with numbers of neurons detected with these markers at $14 \mathrm{~d}$ in the absence of exogenous NGF (Table 2).

\section{Effects of NGF withdrawal on developing cholinergic neurons in sandwich septal cultures}

Since NGF increased the number and size of cholinergic neurons in sandwich cultures at $14 \mathrm{~d}$ in vitro, we assessed whether these neurons were dependent on NGF for survival. NGF was removed from, and antibodies to NGF $(0.2 \%$ goat polyclonal $)$ 
Table 2. Effects of continuous NGF and delayed NGF treatment on septal cholinergic neurons in sandwich cultures

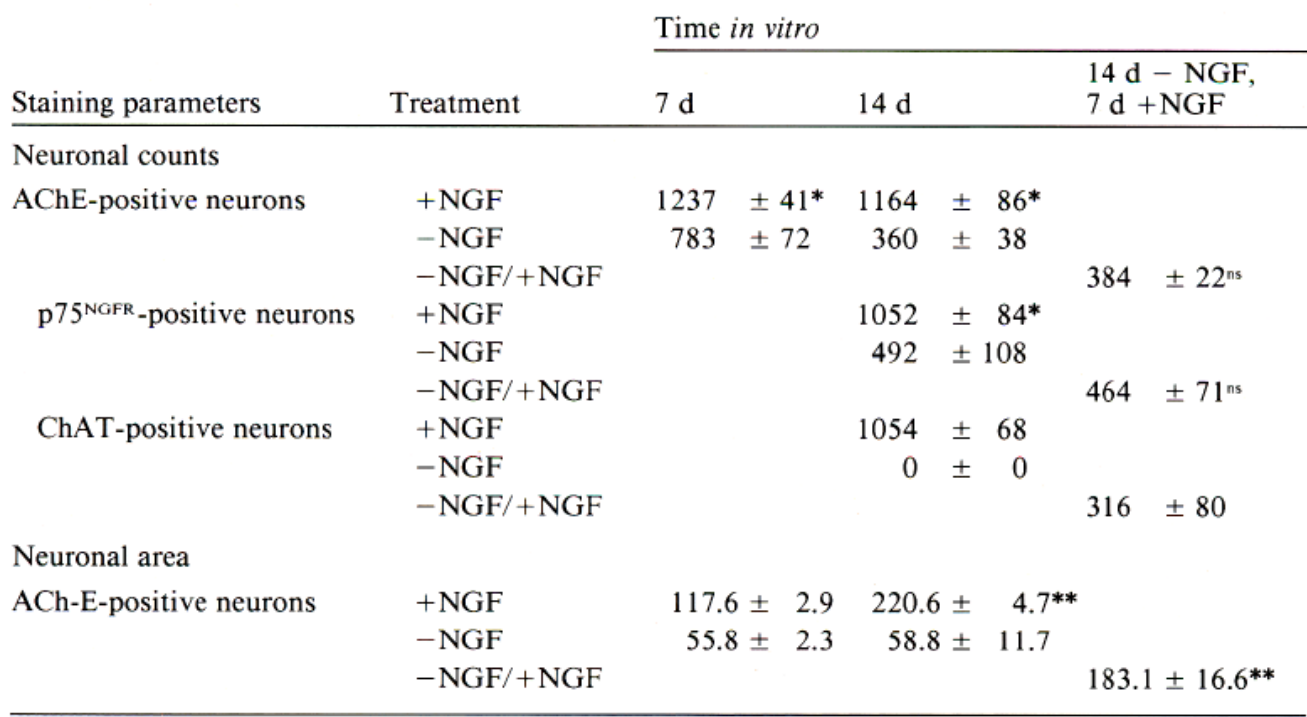

Sister cultures were grown either in the presence (+NGF) or absence (-NGF) of exogenous NGF for 7 or $14 \mathrm{~d}$, or for $14 \mathrm{~d}$ in the absence of NGF followed by $7 \mathrm{~d}$ in the presence of NGF (-NGF/+NGF). Different wells were stained either for AChE, p75 ${ }^{\mathrm{NGFR}}$, or ChAT. Cell counts represent the mean number of stained neurons $/ \mathrm{cm}^{2} \pm \mathrm{SEM}$ ( $n=6 \mathrm{culture}$ wells per group) from a typical experiment using a plating density of approximately $150,000 \mathrm{cells} / \mathrm{cm}^{2}$. Cell areas are in $\mu \mathrm{m}^{2}$ and represent mean of means \pm SEM ( $n=6$ culture wells per group with at least 20 positively stained neurons measured from each well) from a typical experiment.

* Significantly different from corresponding values without NGF, $p<0.01$ ( $t$ test).

** Significantly different from values without NGF and from value with NGF at $7 \mathrm{~d}, p<0.01$ (ANOVA).

$\uparrow$ Significantly different from corresponding value without NGF at $14 d, p<0.01$ (ANOVA).

ns Not significantly different from corresponding values without NGF at $14 \mathrm{~d}$ (ANOVA).

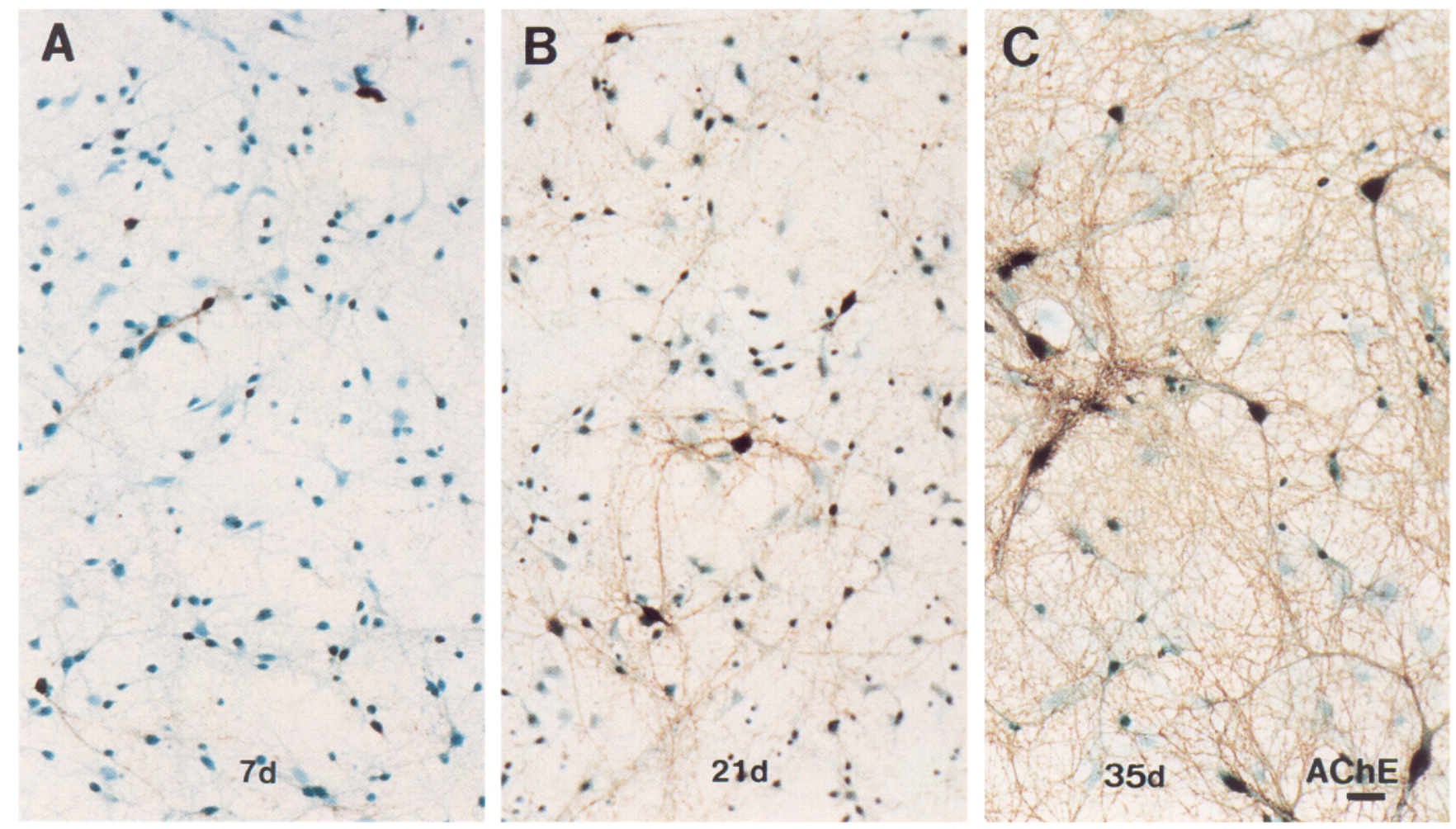

Figure 4. Color photomicrographs showing the gradual maturation of cholinergic neurons and loss of non-cholinergic neurons in septal cultures grown in the continuous presence of exogenous NGF $(100 \mathrm{ng} / \mathrm{ml})$. Different wells from sister cultures plated and grown under identical conditions were harvested and stained for both AChE and LFB at $7 \mathrm{~d}(A), 21 \mathrm{~d}(B)$, and $35 \mathrm{~d}(C)$ in vitro. Over time, the number of the AChE-positive cholinergic neurons (brown) did not change, but these neurons gradually increased both their size and extent of neurite outgrowth. In contrast there was a continuous and substantial reduction in the number of LFB-positive non-cholinergic neurons (dark blue). Scale bar, $75 \mu \mathrm{m}$. 

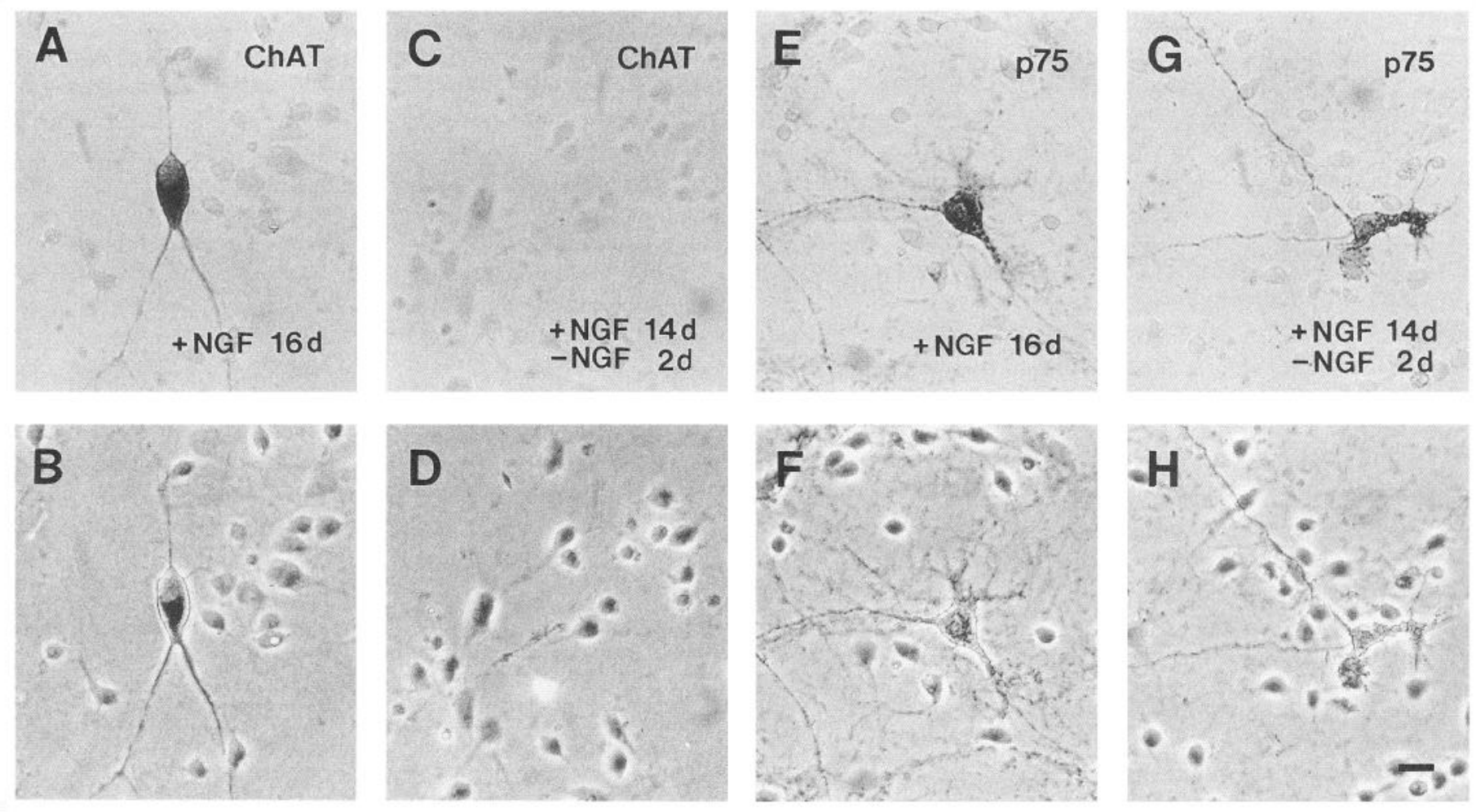

Figure 5. Effects of $2 \mathrm{~d}$ of NGF withdrawal and addition of NGF antibodies on cholinergic neurons in 14-d-old sister sandwich septal cultures previously grown in the continuous presence of NGF $(100 \mathrm{ng} / \mathrm{ml})$. Representative fields from cultures stained for either ChAT $(A-D)$ or p75 NGFR $(E, F)$ are shown using both bright-field $(A, C, E, G)$ and phase-contrast $(B, D, F, H)$ microscopy. Cholinergic neurons grown in the presence of NGF for $16 \mathrm{~d}$ are large and stain intensely for ChAT $(A, B)$ or p $75^{\text {NGFR }}(E, F)$. Withdrawal of NGF for $2 \mathrm{~d}$ from 14 -d-old cultures results in the disappearance of nearly all ChAT-stained $(C)$ and most $\mathrm{p} 75^{\mathrm{NGFR}}$-stained neurons. Remaining p $75^{\mathrm{NGFR}}$-stained neurons are somewhat palely stained, shrunken, and atrophic $(G)$. Withdrawal of NGF for $2 \mathrm{~d}$ has no apparent effect on phase-positive non-cholinergic neurons $(D, H)$. Scale bar, 30 $\mu \mathrm{m}$.

were added to, 14-d-old septal cultures grown continuously in the presence of NGF from plating. At various times following NGF withdrawal in this manner, sister septal cultures were fixed and stained for AChE, ChAT, or p7 $75^{\mathrm{NGFR}}$. After $1 \mathrm{~d}$, the number of neurons stained for these markers declined substantially, and by $2 \mathrm{~d}$ nearly all ChAT-stained and most AChE- or p75 NGFR stained neurons had disappeared (Fig. 6). Most remaining neurons were shrunken and palely stained (Fig. $5 G$ ). By $4 \mathrm{~d}$ after NGF withdrawal, the numbers of ChAT-, AChE-, and p75 $75^{\text {NGFr }}$ -

\section{Table 3. Effects of NGF reapplication at different time points after NGF withdrawal on the survival of septal cholinergic neurons in sandwich septal cultures}

\begin{tabular}{lll} 
Treatment & Neurons & $\begin{array}{l}\text { Percentage of } \\
\text { NGF control }\end{array}$ \\
\hline NGF control & $1380 \pm 36$ & $100 \%$ \\
$3 \mathrm{hr}$ & $1104 \pm 64$ & $80 \%$ \\
$6 \mathrm{hr}$ & $832 \pm 48$ & $60 \%$ \\
$9 \mathrm{hr}$ & $604 \pm 56$ & $44 \%$ \\
$12 \mathrm{hr}$ & $436 \pm 44$ & $32 \%$ \\
$24 \mathrm{hr}$ & $341 \pm 28$ & $25 \%$ \\
$\mathrm{AB}$ control & $256 \pm 44$ & $19 \%$
\end{tabular}

Sister cultures grown in the presence of exogenous NGF for $14 \mathrm{~d}$ were exposed either to NGF antibody for 3-24 hr followed by reapplication of NGF, to NGF antibody without reapplication of $\mathrm{NGF}$ ( $\mathrm{AB}$ control), or to the continued presence of NGF without exposure to NGF antibody (NGF control). After $4 \mathrm{~d}$, cultures were harvested and stained for $\mathrm{p} 75^{\mathrm{NGFR}}$. Cell counts represent the mean number of stained neurons $/ \mathrm{cm}^{2} \pm \operatorname{SEM}$ ( $n=6$ culture wells per group) from a typical experiment. positive neurons were reduced to between $10 \%$ and $25 \%$ of control values (Fig. 6). A number of small, positively stained rounded structures were observed at 2 or $4 \mathrm{~d}$ after NGF withdrawal, which appeared to be cholinergic neurons undergoing a terminal phase of degeneration (Fig. $7 A, B$ ). Eight days after NGF withdrawal, most of these degenerating structures had disappeared. The number of non-cholinergic neurons was not obviously decreased following NGF withdrawal (Fig. $7 A, B$ ).

To assess whether cholinergic neurons in 14-d-old septal cultures exposed to NGF antibody for $4 \mathrm{~d}$ were dead rather than atrophic with downregulated expression of cholinergic marker proteins, NGF was reapplied by removing medium containing NGF antibody, washing cultures two times in fresh medium, and replacing NGF $(100 \mathrm{ng} / \mathrm{ml})$ to the final medium. Four days of NGF reapplication did not increase the number of AChE-, p75 NGFR - , or ChAT-positive neurons in cultures that had been exposed to NGF antibody for $4 \mathrm{~d}$ (Fig. 6). We next determined the duration of NGF withdrawal required for cholinergic neurons to become irreversibly committed to cell death. Fourteenday-old septal cultures were exposed to NGF antibody for 3$24 \mathrm{hr}$, followed by reapplication of NGF for $4 \mathrm{~d}$. NGF reapplication rescued most cholinergic neurons after $3 \mathrm{hr}$ of NGF withdrawal, but progressively fewer cholinergic neurons survived after 6 or $9 \mathrm{hr}$. When NGF reapplication was delayed for 12 or $24 \mathrm{hr}$ the number of neurons surviving was not substantially higher than if NGF was not reapplied at all (Table 3).

To test whether some factor in the polyclonal goat antibody used to neutralize NGF may have had a nonspecific toxic effect on cholinergic neurons, a different anti-NGF was used. A mouse 


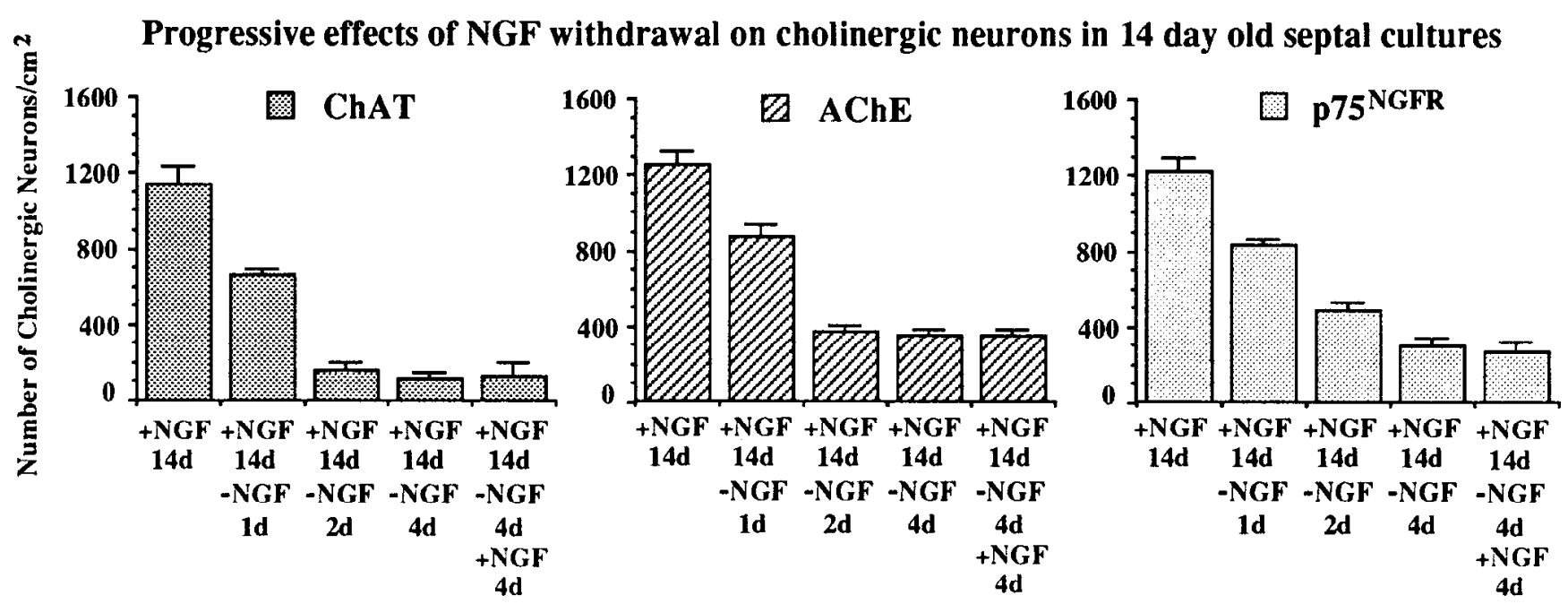

Figure 6. Graph showing the effects of NGF withdrawal on developing cholinergic neurons in vitro. Five groups of sandwich septal cultures were grown in the continuous presence of exogenous NGF $(100 \mathrm{ng} / \mathrm{ml})$ for $14 \mathrm{~d}$. NGF was then withdrawn and NGF antibodies added to four groups. Cultures were harvested at $14 \mathrm{~d}(+N G F)$, at 1,2 , and $4 \mathrm{~d}$ after NGF withdrawal $(-N G F)$, and after $4 \mathrm{~d}$ of NGF withdrawal $(-N G F)$ followed by reapplication of NGF $(100 \mathrm{ng} / \mathrm{ml})$ for a further $4 \mathrm{~d}(+N G F)$. Cultures were stained for ChAT, p $75^{\mathrm{NGFR}}$, or AChE, and the number of positive neurons counted in five fields per culture well and extrapolated to neurons $/ \mathrm{cm}^{2} . N=6$ culture wells per data point ( \pm SEM) from a typical set of experiments. All values from $2 \mathrm{~d}-N G F, 4 \mathrm{~d}-N G F$, and $4 \mathrm{~d}-\mathrm{NGF}$ followed by $4 \mathrm{~d}+\mathrm{NGF}$ groups were significantly different from their respective control valucs of $14 \mathrm{~d}$ I NGF (ANOVA, $p<0.01$ ). This experiment was conducted three times with similar results.

monoclonal NGF antibody $(30 \mu \mathrm{g} / \mathrm{ml})$ also reduced the number of AChE-positive neurons detectable at 4 d post-NGF withdrawal to approximately $25 \%$ of control values (not shown).

\section{Septal cholinergic neurons lose their dependence on NGF as they mature in vitro}

Sensory, but not sympathetic, peripheral neurons grown in tissue culture lose their dependence on NGF with increasing time in vitro (Greene, 1977a,b; Barde et al., 1980; Schwartz et al., 1982). To test whether cholinergic septal neurons might similarly lose their dependence on NGF as they mature, NGF was removed and NGF antibody ( $0.2 \%$ goat polyclonal) added for $4 \mathrm{~d}$ to either 14- or 35-d-old sister cultures and the number of remaining cholinergic neurons was compared with sistcr cultures continually exposed to NGF. The survival time of $4 \mathrm{~d}$ was chosen since most cholinergic neurons in 14-d-old cultures become committed to cell death after $12 \mathrm{hr}$ of NGF-withdrawal and have disappeared by $48 \mathrm{hr}$. Consistent with the experiments described above, when NGF was withdrawn for $4 \mathrm{~d}$ from 14d-old septal cultures only about $25 \%$ the number of ChAT-, AChE-, or $\mathrm{p} 75^{\mathrm{NGFR}}$-stained neurons could be detected relative to the number of cholinergic neurons in cultures maintained in NGF for $18 \mathrm{~d}$ (Figs. 7, 8). In contrast, when NGF was withdrawn for $4 \mathrm{~d}$ from 35 -d-old sister cultures more than $75 \%$ of cholinergic neurons could be detected with all three of these markers (Figs. 7, 8). The remaining cholinergic neurons, however, were significantly shrunken (mean cross-sectional area of $169.6 \pm$ $55.4 \mu \mathrm{m}^{2} ; p<0.001$ vs. control, $t$ test) in comparison to cholinergic neurons in cultures maintained in NGF for $39 \mathrm{~d}$ ( 247.8 $\left.\pm 64.1 \mu \mathrm{m}^{2}\right)$.

\section{Death of immature cholinergic neurons induced by NGF withdrawal is dependent on protein synthesis}

Inhibition of protein synthesis significantly attenuates the death of developing sympathetic neurons grown in vitro in the absence of NGF (Martin et al., 1988; Edwards et al., 1991). To inves- tigate whether the death of septal cholinergic neurons following NGF withdrawal at $14 \mathrm{~d}$ in vivo might also depend on protein synthesis, we administered cycloheximide to septal cultures in combination with NGF withdrawal. The concentration of cycloheximide used for cultures of sympathetic neurons $(1 \mu \mathrm{g} / \mathrm{ml}$; Martin et al., 1988) was toxic to 14-d-old septal neurons such that over $80 \%$ died within $24 \mathrm{hr}$ (data not shown). The highest concentration of cycloheximide tested that did not kill septal neurons over a $4 \mathrm{~d}$ period was $0.1 \mu \mathrm{g} / \mathrm{ml}$. This concentration of cycloheximide prevented glial division in open-faced high-density septal cultures and was considered effective in preventing protein synthesis. Fourteen-day-old sandwich septal cultures exposed to cycloheximide at this concentration for $4 \mathrm{~d}$ in the continuous presence of NGF had about $75 \%$ the number of AChE-positive neurons and somewhat reduced numbers of AChE-positive fibers when compared with sister cultures treated with NGF alone (Fig. 9). As expected, 14-d-old cultures deprived of NGF and given NGF antibody for $4 \mathrm{~d}$ had only about $25 \%$ the number of AChE-positive neurons when compared with NGF-treated cultures (Fig. 9E,F,I). In contrast, 14-d-old cullures deprived of NGF and given NGF antibody for $4 \mathrm{~d}$ in the presence of cycloheximide had about $75 \%$ the number of AChE-positive neurons when compared with NGF-treated cultures, in a manner not significantly different than cultures treated with NGF and cycloheximide (Fig. 9G-I). Exposure to NGF antibodies or cycloheximide had no apparent effect on noncholinergic neurons (Fig. 9).

\section{Discussion}

In this study, the sandwich culture technique significantly increased the survival of neurons, reduced glial proliferation, and after $5 \mathrm{~d}$ in vitro allowed the transfer of septal cultures to a serum-free, completely defined growth medium for long-term maintenance of cholinergic neurons. Using this method, we found that withdrawal of NGF from 14-d-old septal cultures grown in the presence of exogenous NGF from plating resulted in the 

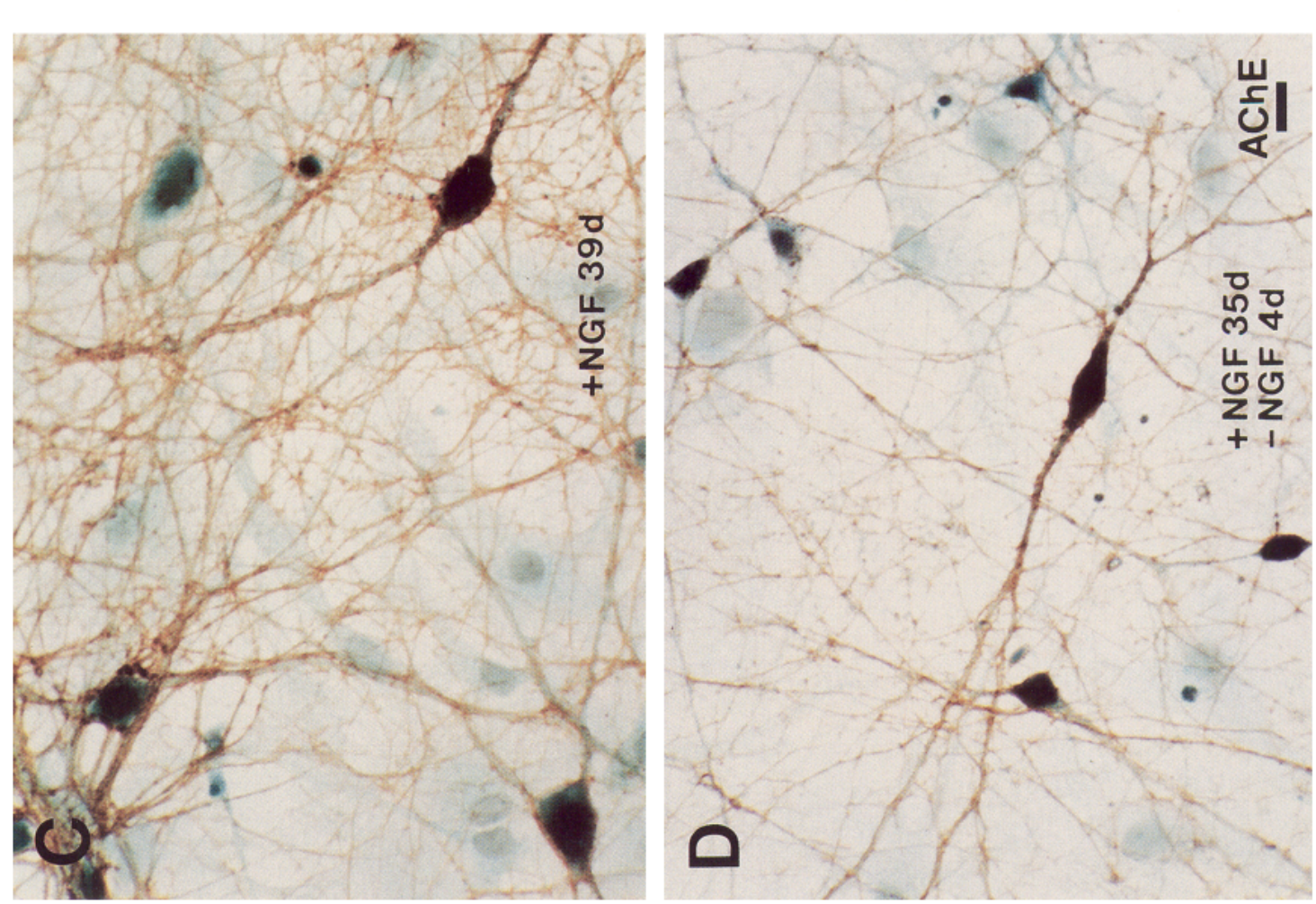

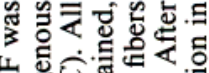

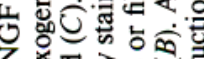

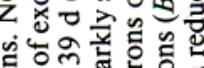

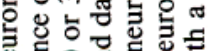

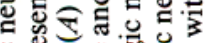

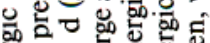

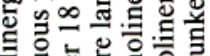

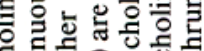
을

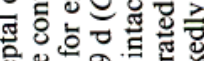
○.

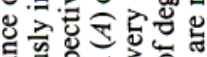

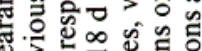

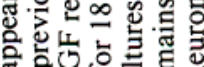

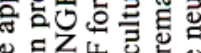

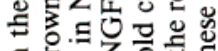
ธ。

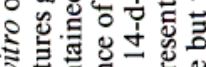

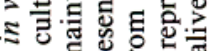
业

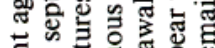

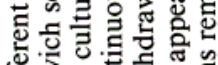

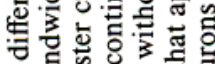

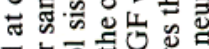
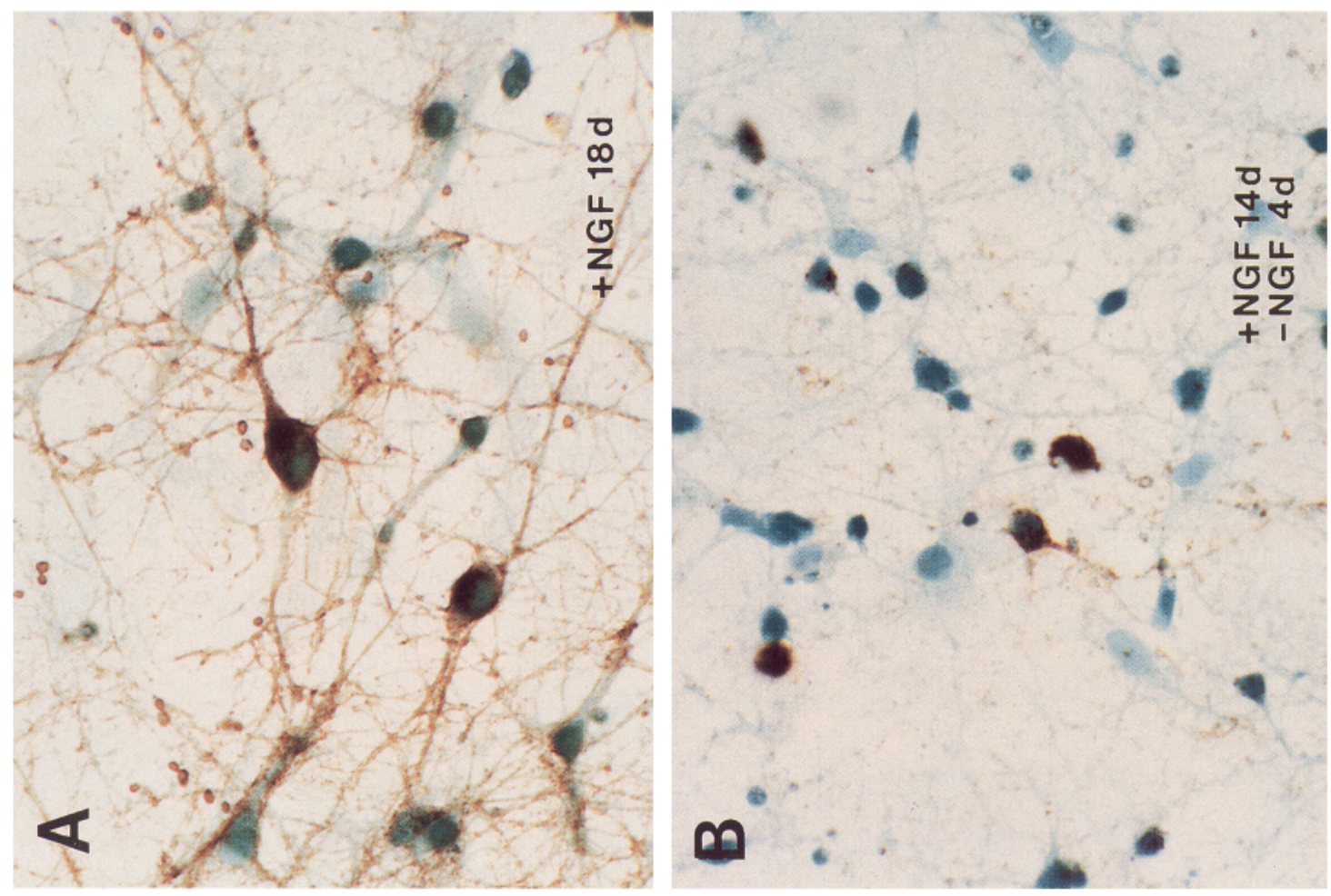

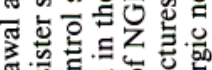

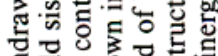

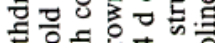

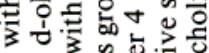

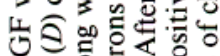

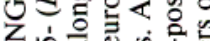

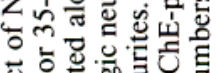

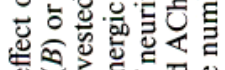

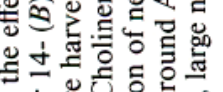

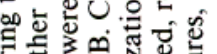

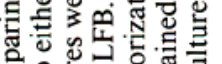

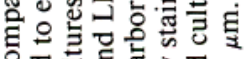

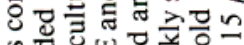

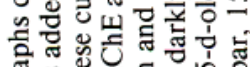

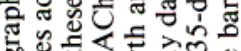
of.0 象十

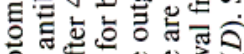

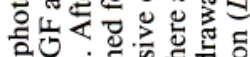

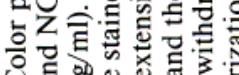
○ 등요

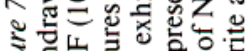

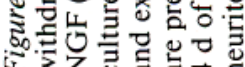



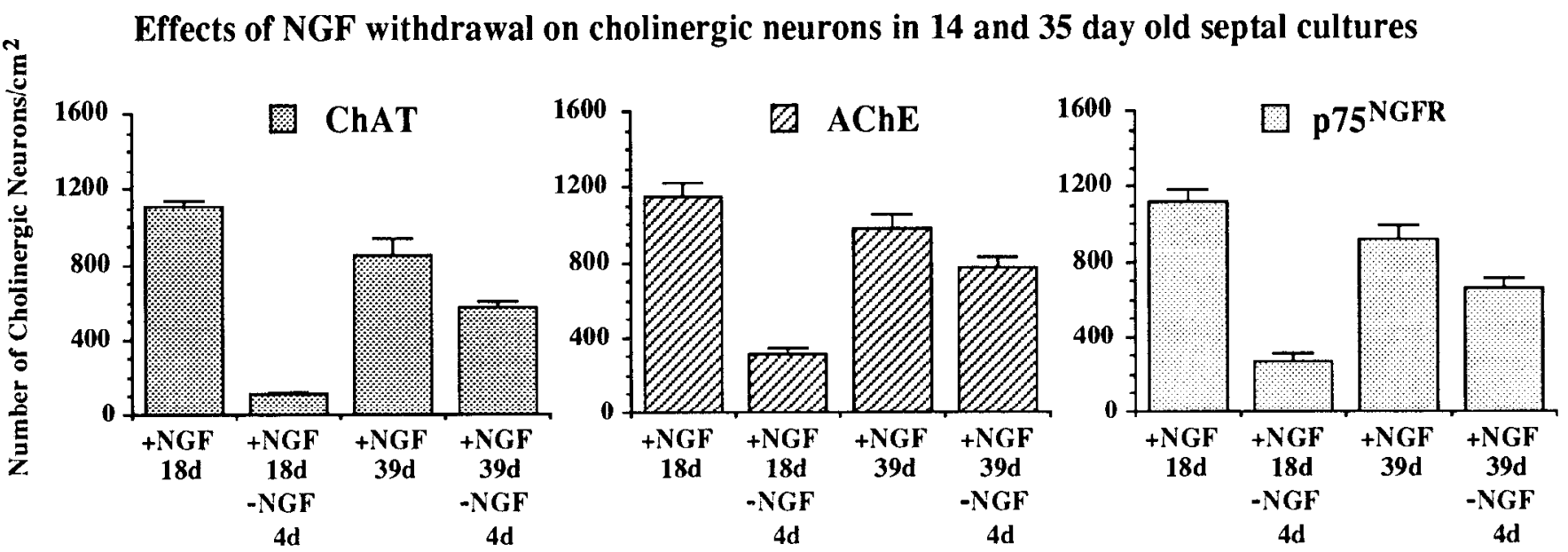

Figure 8. A, Graph comparing the effect of NGF withdrawal at different ages in vitro on cell counts of septal cholinergic neurons. Four groups of sandwich septal cultures were grown in the continuous presence of exogenous NGF $(100 \mathrm{ng} / \mathrm{ml})$ for either 14 or $35 \mathrm{~d}$. NGF was then withdrawn and NGF antibodies added to one group at each time point and after a further $4 \mathrm{~d}$, all cultures were harvested. The number of neurons stained for ChAT, p75 NGFR, or AChE were counted in five fields per culture well and extrapolated to neurons $/ \mathrm{cm}^{2} . N=6 \mathrm{culture}$ wells per data point $( \pm$ SEM) from a typical experiment. This experiment was conducted three times with similar results. For each marker, values from groups exposed to NGF withdrawal at 14 or $35 \mathrm{~d}$ are significantly different from from each other and from values of their respective control groups given NGF for 18 or $39 \mathrm{~d}($ ANOVA, $p<0.01)$.

widespread death of cholinergic neurons, whereas in 35-d-old sister cultures most cholinergic neurons survived NGF withdrawal. In addition, the cholinergic cell death associated with NGF withdrawal from 14-d-old cultures was significantly attenuated by inhibition of protein synthesis. These findings raise a number of questions about the protective effects of the sandwich culture techniques and the role of NGF regarding developing and maturing septal cholinergic neurons.

\section{Methodological considerations}

Using standard open-faced culture methods, embryonic neurons from the septal region undergo massive neuronal cell death over the first few days in vitro (Hartikka and Hefti, 1988; Alderson et al., 1990; present results). Although this cell death might be reduced by addition of certain chemical supplements to the growth medium, the use of such additives would complicate the interpretation of studies intended to characterize the effects of a neurotrophic factor. We therefore grew septal neurons in unsupplemented medium under glass coverslips using a sandwich technique previously shown to increase neuronal survival and reduce glial proliferation in hippocampal cultures (Brewer and Cotman, 1989).

We found that the sandwich culture technique substantially increased general neuronal survival in septal cultures but did not prevent the eventual death of most cholinergic neurons grown in the absence of exogenous NGF. In addition, in septal cultures maintained for long periods of time in the presence of NGF but not other growth factors there was a gradual loss of non-cholinergic neurons, while cholinergic neurons thrived. The sandwich culture technique also did not prevent the rapid death of DRG neurons grown in the absence of NGF. Embryonic DRG neurons at the age used in this study are completely dependent on NGF for survival in vivo (Johnson et al., 1980) and in vitro (Levi-Montalcini and Angeletti, 1963). Various lines of evidence suggest that very young neurons are initially not dependent for survival on specific target-derived growth factors, but become dependent during a critical period and may eventually lose this dependence as they mature (Purves and Lichtman, 1985). Thus, it appears that the sandwich culture technique may be able to improve the survival of neurons in some general way during phases when they do not have specific growth factor requirements, but cannot protect neurons from the lack of specific growth factors during critical periods of development. In addition, the sandwich method substantially improved the longterm maintenance and maturation of neurons provided with their specific growth factor requirements in a serum-free and completely defined medium.

The mechanism underlying the protective effect of the sandwich technique on general neuronal survival is not fully understood. It has been reported in both hippocampal and cortical cultures that lowering the oxygen concentration inside the incubator from $20 \%$ to $9 \%$ can reduce the postplating cell death to about the same amount seen in sandwich cultures (Kaplan et al., 1986; Brewer and Cotman, 1989; Kushima et al., 1990). Reduced oxygen concentrations may exist within sandwich cultures as a result of the metabolism of cells within a small, slowly circulating diffusion layer.

Between 7 and $14 \mathrm{~d}$ in vitro our sandwich septal cultures underwent a substantial decline in the total number of neurons. While this decline might reflect the dependence of neurons on specific growth factors during this period, it might also be due to an increased requirement for oxygen in more mature neurons as suggested for telencephalic aggregating cultures and postnatal septal cultures (Honegger, 1985; Kushima et al., 1990). Low oxygen concentration might also be responsible for the variable amount of necrotic cell death at the very center of sandwich cultures noted after long survival times in this study and in hippocampal cultures (Brewer and Cotman, 1989).

Neuronal survival might also be improved in sandwich culturcs by the smaller volume of circulating medium into which growth factors and other molecules might be released from neighboring cells. Thermal proteins and poly(dicarboxylic) amino acids have also recently been shown specifically to enhance the survival of septal neurons in culture (Hefti et al., 1991), and similar substances might be produced by neurons or glia. Last, sandwich cultures provide an artificial three-dimensional en- 

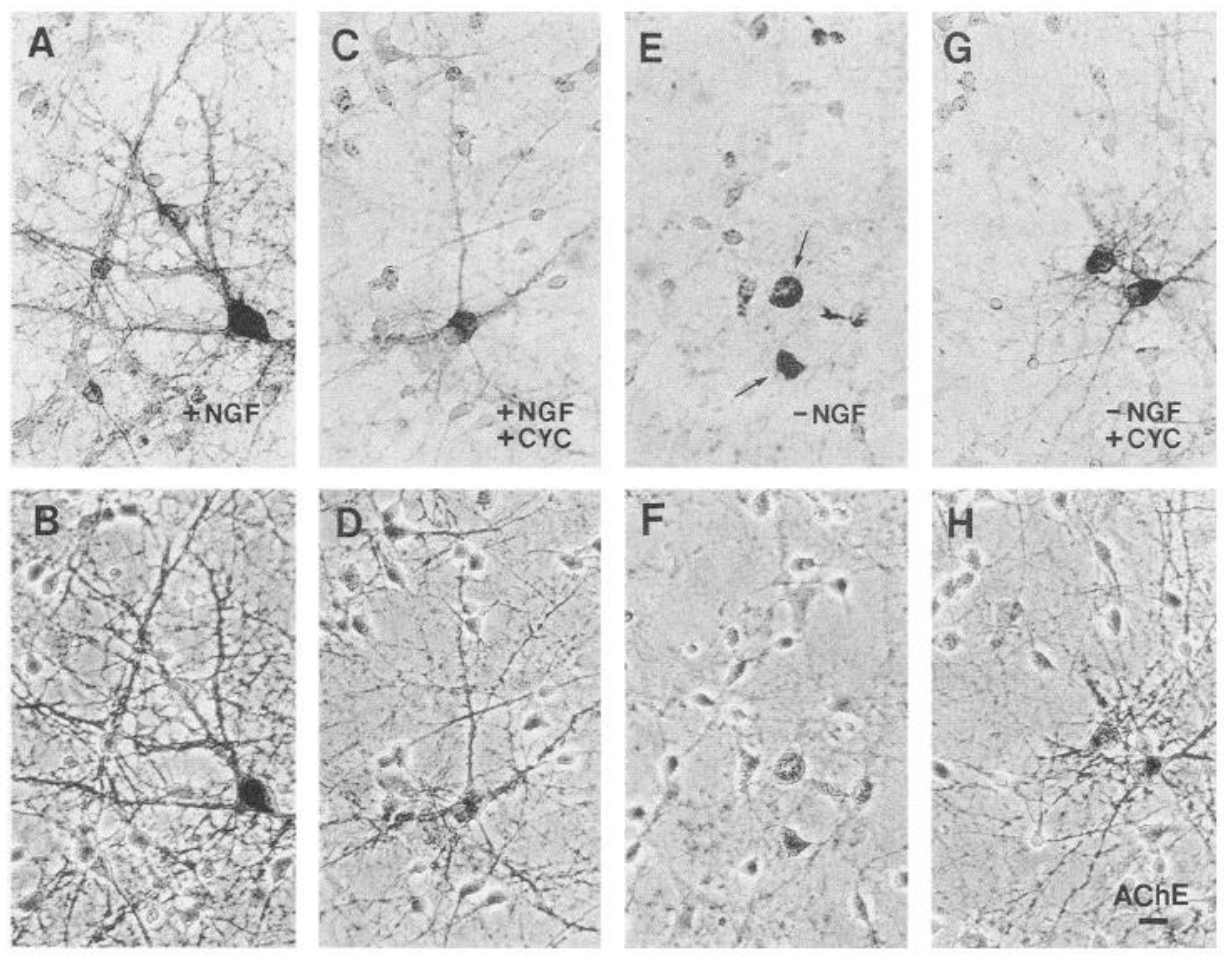

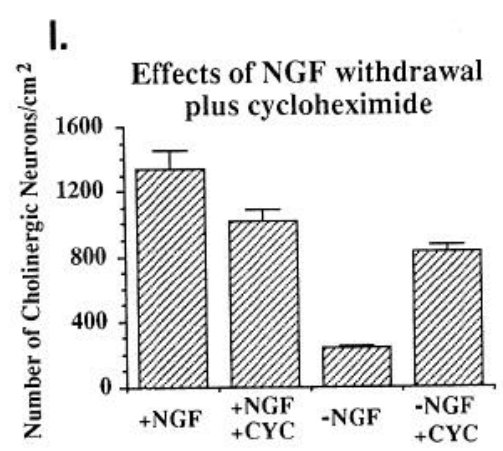

Figure 9. Qualitative $(A-H)$ and quantitative $(I)$ comparison of the effects of NGF withdrawal in the presence or absence of the protein synthesis inhibitor cycloheximide on the appearance of septal cholinergic neurons. Sister sandwich septal cultures were grown for $14 \mathrm{~d}$ in the continuous presence of NGF $(100 \mathrm{ng} / \mathrm{ml})$, divided into four groups, and grown a further $4 \mathrm{~d}$ in NGF $(+N G F ; A, B)$, NGF plus cycloheximide $(0.1 \mu \mathrm{g} / \mathrm{ml})$ $(+N G F /+C Y C ; C, D)$, antibodies to NGF $(-N G F ; E, F)$, and antibodies to NGF plus cycloheximide $(0.1 \mu \mathrm{g} / \mathrm{ml})(-N G F /+C Y C ; G, H)$. At 18 $\mathrm{d}$, cultures were harvested and stained for AChE. $A-H$, Representative fields from each experimental condition are shown using both bright-field $(A, C, E, G)$ and phase-contrast $(B, D, F, H)$ microscopy. Cholinergic neurons grown in the presence of NGF for $18 \mathrm{~d}$ are large and darkly stained, and exhibit extensive outgrowth and arborization of neurites $(A, B)$. Exposure to cycloheximide for $4 \mathrm{~d}$ in the presence of NGF leads to a slight reduction in neuronal number and in the staining intensity of some neurons $(C, D)$. After exposure to NGF antibodies for $4 \mathrm{~d}$, few cholinergic neurons or fibers remain, but there are a number of darkly stained, round, AChE-positive structures (arrows) that probably represent degenerated neurons $(E, F)$. When protein synthesis is inhibited with cycloheximide in combination with exposure to NGF antibodies for $4 \mathrm{~d}$, there is only a slight reduction in the number and appearance of cholinergic neurons and there are no obviously degenerated structures $(G, H)$. Treatment with NGF antibodies or cycloheximide has no obvious effect on the number or appearance of non-cholinergic neurons $(B, D, F, H)$. Scale bar, $30 \mu \mathrm{m}$. $I$, Graph comparing the effects NGF withdrawal in the presence or absence of the protein synthesis inhibitor cycloheximide on cell counts of septal cholinergic neurons. The number of positive cholinergic neurons was counted in five fields per culture well and extrapolated to neurons/ $\mathrm{cm}^{2} . N=$ 6 culture wells per data point $( \pm$ SEM) from a typical experiment. This experiment was conducted three times with similar results. For AChEpositive neurons, $+N G F /+C Y C$ and $-N G F /+C Y C$ groups were not significantly different from each other but were both significantly different from the $-N G F$ group, and all three of these groups were significantly different from $+N G F$ (ANOVA, $p<0.01$ ).

vironment for neurons, which may increase the survival of septal neurons through augmented surface contact.

The sandwich culture technique also markedly decreased glia proliferation and increased glial differentiation. The decreased survival of DRG neurons in sandwich cultures may be related to this effect since glial cells produce various growth factors including NGF (Lindsay, 1979). Reduced glial proliferation may add to the usefulness of sandwich cultures in studying neuronal growth factor requirements under defined conditions.

\section{NGF increases cholinergic but not general neuronal survival and maturation in septal cultures}

Exogenous NGF increases the survival of cholinergic neurons in septal cultures at plating densities of under 150,000 cells $/ \mathrm{cm}^{2}$ (Hartikka and Hefti, 1988), but does not appear to increase the number of detectable cholinergic neurons in open-faced cultures at higher plating densities. In this study, NGF added from plating also substantially increased the number of cholinergic neurons identified by staining for three well-documented cholinergic markers, AChE, p75 $5^{\text {NGFR }}$, and ChAT (Eckenstein and Sofroniew, 1983; Dawbarn et al., 1988), in sandwich septal cultures at low plating densities $\left(150,000\right.$ cells $\left./ \mathrm{cm}^{2}\right)$. Interestingly, a small number of AChE- and p $75^{\text {NGFR }}$ - but no ChAT-stained neurons were consistently detectable in sandwich septal cultures grown in the absence of exogenous NGF. The observation that delayed addition of NGF at $14 \mathrm{~d}$ in vitro failed to increase the number of $\mathrm{AChE}$ or $\mathrm{p} 75^{\mathrm{NGFR}}$ neurons strongly suggests that the increase in cholinergic cell number seen with the addition of NGF from plating was an effect on cell survival rather than on cell phenotype. Moreover, the small number of $\mathrm{AChE}$ and p $75^{\mathrm{NGFR}}$ neurons seen in the absence of exogenous NGF appear to be cholinergic, since the delayed addition of NGF increased the number and size of ChAT neurons to a level equivalent to those of $\mathrm{AChE}$ and p $75^{\mathrm{NGFR}}$ neurons in similarly treated sister wells. It is not clear whether the small number of cholinergic cells surviving in the absence of exogenous NGF were growth factor independent, or were being maintained by growth factors being produced by cells within the culture. We now have evidence 
that growth factors other than NGF can maintain the survival but not the phenotype of cholinergic neurons in these cultures (Kew et al., 1992).

Sandwich cultures also allowed the the long-term maintenance and gradual maturation of cholinergic neurons at low cell density. In open-faced culture systems, long-term survival of septal cholinergic neurons is only possible either when very high initial plating densities are used $\left(300,000 \mathrm{cells} / \mathrm{cm}^{2}\right.$ or more) or when glial cells are allowed to divide and form a supportive monolayer (Hartikka and Hefti, 1988). In contrast, the sandwich culture technique permitted the gradual maturation and longterm maintenance, for over $40 \mathrm{~d}$, of large numbers of cholinergic neurons in septal cultures at low total neuronal densities $\left(<150,000\right.$ cells $\left./ \mathrm{cm}^{2}\right)$ in serum-free, completely defined NGFcontaining medium, with only a sparse glial population. It deserves mention that the maturation of cholinergic neurons in sandwich septal cultures roughly parallels the development of these neurons in vivo. In sandwich cultures, the size of NGFsupplemented cholinergic neurons increased substantially between 7 and $21 \mathrm{~d}$ in vitro. This compares favorably with reports that both ChAT- and $\mathrm{p} 75^{\mathrm{NGFR}}$-stained basal forebrain neurons undergo pronounced increases in cell size during the third week of postnatal development (Sofroniew et al., 1987; Koh and Loy, 1989 ) in parallel with a surge in hippocampal production of NGF (Auburger et al., 1987). Thus, the sandwich culture technique provides a means of studying mature septal cholinergic neurons in vitro under precisely defined conditions.

NGF has also been reported to increase general neuronal survival at very low plating densities of less than 17,000 neurons/ $\mathrm{cm}^{2}$ (Grothe et al., 1989), but this observation has not been confirmed by others (Knusel et al., 1990). In both our sandwich and open-faced culture conditions NGF had no effect on general neuronal survival in septal cultures at any plating density tested, including those as low 5000 or 10,000 neurons $/ \mathrm{cm}^{2}$, supporting the view that the survival-promoting effects of NGF are limited to cholinergic neurons in septal cultures.

\section{Developing but not mature septal cholinergic neurons are dependent on NGF for survival in vitro}

Since the degree to which NGF regulates the survival of developing or mature basal forebrain cholinergic neurons is not well understood, we studied the effects of NGF withdrawal from septal cholinergic neurons that had been allowed to achieve different stages of maturity in the presence of NGF under precisely defined conditions in sandwich cultures. Antibody-mediated withdrawal of NGF at $14 \mathrm{~d}$ in vitro led to the disappearance and presumed death of about $75 \%$ of developing septal cholinergic neurons stained for ChAT, AChE, or $\mathrm{p} 75^{\mathrm{NGFR}}$. Since axotomized cholinergic neurons can become atrophic and lose their staining for cholinergic markers without dying (Lams et al., 1988), an additional study was conducted. Reapplication of NGF to septal cultures for $4 \mathrm{~d}$ after NGF withdrawal failed to increase the number of ChAT, AChE, or p $75^{\mathrm{NGFR}}$ neurons, suggesting that the cells that had disappeared were indeed dead rather than merely downregulated in the absence of NGF. The effects of NGF withdrawal on developing septal cholinergic neurons appear to be mediated rapidly. Whereas reapplication of NGF after 3 hr of exposure to NGF antibody rescued cholinergic neurons, our findings suggest that $12 \mathrm{hr}$ of NGF withdrawal is sufficient to commit most developing cholinergic neurons to cell death.

In contrast to our findings in vitro, injection of NGF anti- bodies into the ventricles of neonatal rats at a similar developmental age does not lead to a permanent decline in ChAT activity in the cholinergic basal forebrain (Gnahn et al., 1983; Vantini et al., 1989), suggesting that NGF antibody administration in vivo does not kill developing basal forebrain cholinergic neurons. There are several possible explanations for this apparent discrepancy in findings. First, it is possible that antibodies do not penetrate well into brain tissue in vivo and are not able to neutralize enough NGF to affect the survival of dependent neurons. In support of this explanation, a study on the sprouting of sympathetic neurons into the injured hippocampus shows that the effects of infused NGF antibody are very restricted around the infusion site (Springer and Loy, 1985). Another possible explanation is that other growth factors produced in the hippocampus, such as brain-derived neurotrophic factor (Alderson et al., 1990), may be able to sustain the survival of septal cholinergic neurons in the absence of NGF. Last, both of the above-mentioned in vivo studies measured ChAT activity but did not count the number of histologically detectable cholinergic neurons. It is well documented that levels of ChAT activity will initially decline and then return to near normal levels in the basal forebrain cholinergic system in spite of the experimentally induced loss or degeneration of ChAT-producing neurons (Wenk and Olton, 1984; Stephens et al., 1985). Thus, biochemical determination of ChAT activity in tissue homogenates is not a reliable indicator of the presence or absence of cholinergic cell death in experimental studies.

We also examined whether septal cholinergic neurons remained dependent on NGF for survival as they matured in vitro. In contrast to the massive cell death triggered within $12 \mathrm{hr}$ of NGF withdrawal at $14 \mathrm{~d}$ in vitro, over $75 \%$ of septal cholinergic neurons survived $4 \mathrm{~d}$ of antibody-mediated withdrawal of NGF at $35 \mathrm{~d}$ in vitro. Although it might be argued that the mature neurons are simply taking longer to degenerate, these findings are consistent with observations made in vivo that developing but not mature septal cholinergic neurons degenerate after lesions that deprive them of neurotophins (including NGF) provided by target neurons (Sofroniew et al., 1990, 1993; Cooper and Sofroniew, 1992). These findings also agree well with previously described changes in the NGF dependence of certain peripheral neurons. Developing DRG neurons are absolutely dependent on NGF for survival but become gradually less dependent on NGF for survival as they mature both in vivo and in vitro (Greene, 1977b; Barde et al., 1980; Schwar7 et al., 1982). Moreover, it appears that the absolute age of the DRG neuron, rather than the time in culture, determines when neurotrophic independence will begin (Eichler and Rich, 1989). This observation suggests that an intrinsic clock regulates the timing of NGF dependence in DRG neurons. It remains to be determined whether the timing of NGF dependence in septal cholinergic neurons is internally regulated in a similar manner.

\section{$N G F$ withdrawal-mediated death of developing septal cholinergic neurons in vitro requires protein synthesis}

Naturally occurring cell death is an essential feature of neural development and appears to be regulated at least in part by the availability to neurons of specific growth factors (Oppenheim, 1989). Considerable evidence suggests that developmental cell death in certain non-neural tissues occurs via receptor-mediated apoptosis activated by environmental cues that trigger an intrinsic program leading to cell death (Wyllie et al., 1980; Arends et al., 1990). In agreement with this possibility, inhibition of 
protein synthesis can block developmental cell death in both non-neural and neural tissue (McConkey et al., 1988; Oppenheim et al., 1990). Moreover, the death of developing sympathetic neurons induced by NGF withdrawal in vitro can be prevented by blockade of protein synthesis (Martin et al., 1988; Edwards et al., 1991). In this study we found that blockade of protein synthesis also protects developing septal cholinergic neurons from the cell death induced by NGF withdrawal in vitro. This finding suggests that growth factor-regulated developmental cell death may also occur in CNS neurons via activation of programmed cell death requiring protein synthesis. Although the underlying mechanism is not understood, it has been suggested that withdrawal of NGF from sympathetic neurons leads to either the de novo expression of lethal proteins (Martin et al., 1988) or the activation of constitutively produced lethal proteins (Batistatou and Greene, 1991).

\section{Neurotrophic regulation of naturally occurring developmental cell death in septal cholinergic neurons}

No direct evidence has yet been provided demonstrating that naturally occurring cell death does or does not take place during the development of septal cholinergic neurons, or that such a process might be regulated by a neurotrophic factor like NGF. Addressing this question is difficult because cholincrgic ncurons comprise only a small proportion of septal cells and can only be identified by chemical phenotype. The problems associated with trying to estimate cell survival based only on chemical markers has been discussed. Nevertheless, naturally occurring developmental cell death has been described in various CNS regions (Purves and Lichtman, 1985; Ferrer et al., 1990). Our findings indicate that septal cholinergic neurons grown in the presence of NGF in tissue culture under defined conditions become dependent on NGF for survival during a critical phase during development and lose this dependence as they mature in vitro. These findings are compatible with the observation that ablation of hippocampal neurons and reduction of hippocampal NGF mRNA by over $90 \%$ leads to the loss of septal cholinergic neurons in neonatal but not adult or aged rats (Sofroniew et al., 1990, 1991; Cooper et al., 1991; Cooper and Sofroniew, 1992). Moreover, the cell death induced in developing septal cholinergic neurons by NGF withdrawal in vitro can be attenuated by inhibition of protein synthesis in a manner similar to growth factor-regulated developmental cell death in other neuronal and non-neuronal cells. Together these findings suggest that NGF might participate in regulating the survival of septal cholinergic neurons during a critical period of development.

\section{References}

Alderson RF, Alterman AL, Barde YA, Lindsay RM (1990) Brainderived neurotrophic factor increases survival and differentiated functions of rat septal cholinergic neurons in culture. Neuron 5:297-306.

Arends MJ, Morris RG, Wyllie AH (1990) Apoptosis: the role of endonuclease. Am J Pathol 136:593-608.

Auberger G, Heumann R, Hellweg R, Korsching S, Thoenen H (1987) Developmental changes of nerve growth factor and its mRNA in the rat hippocampus: comparison with choline acetyltransferase. Dev Biol 120:322-328.

Barde YA, Edgar D, Thoenen H (1980) Sensory neurons in culture: changing requirements for survival factors during embryonic development. Proc Natl Acad Sci USA 77:1199-1203.

Batistatou A, Greene LA (1991) Aurintricarboxylic acid rescues PC12 cells and sympathetic neurons from cell death caused by nerve growth factor deprivation: correlation with suppression of endonuclease activity. J Cell Biol 115:461-471.
Brewer GJ, Cotman CW (1989) Survival and growth of hippocampal neurons in defined medium at low density: advantage of a sandwich culture technique or low oxygen. Brain Res 494:65-74.

Cooper JD, Sofroniew MV (1992) Death of septal cholinergic neurons following ablation of target neurons in neonatal pups. Soc Neurosci Abstr 18:774.

Cooper JD, Svendsen CN, Stevens SJ, Baker KJ, Sofroniew MV (1991) Aged rats down-regulate immunoreactive ChAT but not NGFr in septal cholinergic neurons after loss of hippocampal target neurons. Soc Neurosci Abstr 17:221.

Dawbarn D, Allen SJ, Semenenko FM (1988) Coexistance of choline acetyltransferase and nerve growth factor receptors in the rat basal forebrain. Neurosci Lett 94:138-164.

Eckenstein F, Sofroniew MV (1983) Identification of central cholinergic neurons containing both choline acetyltransferase and acetylcholinesterase and of central neurons containing only acetylcholinesterase. J Neurosci 3:2286-2291.

Edwards SN, Buckmaster AE, Tolkovsky AM (1991) The death programme in cultured sympathetic neurons can be suppressed at the posttranslational level by nerve growth factor, cyclic AMP, and depolarization. J Neurochem 57:2140-2144.

Eichler ME, Rich KM (1989) Death of sensory ganglion neurons after acute withdrawal of nerve growth factor in dissociated cell cultures. Brain Res 482:340-346.

Ferrer I, Bernet E, Soriano E, del Rio T, Fonseca M (1990) Naturally occurring cell death in the cerebral cortex of the rat and removal of dead cells by phagocytes. Neuroscience 39:451-458.

Gnahn H, Hefti F, Heumann R, Schwab ME, Thoenen H (1983) NGFmediated increase of choline acetyltransferase (ChAT) in the neonatal rat forebrain: evidence for a physiological role of NGF in the brain. Dev Brain Res 9:45-52.

Gorin PD, Johnson EM (1979) Effects of long term nerve growth factor deprivation on the nervous system of the adult rat: an experimental autoimmune approach. Brain Res 198:27-42.

Greene LA (1977a) Quantitative in vitro studies on the nerve growth factor (NGF) requirement of neurons. I. Sympathetic neurons. Dev Biol 58:96-105.

Greene LA (1977b) Quantitative in vitro studies on the nerve growth factor (NGF) requirement of neurons. II. Sensory neurons. Dev Biol 58:106-113.

Grothe C, Otto D, Unsicker K (1989) Basic fibroblast growth factor promotes in vitro survival and cholinergic development of rat septal neurons: comparison with the effects of nerve growth factor. Neuroscience 31:649-661.

Hartikka J, Hefti F (1988) Development of septal cholinergic neurons in culture: plating density and glial cells modulate effects of NGF on survival, fibre growth, and expression of transmitter-specific enzymes. J Neurosci 8:2967-2985.

Hefti F (1986) Nerve growth factor promotes survival of septal cholinergic neurons after fimbrial transections. J Neurosci 6:2155-2162.

Hefti F, Hartikka J, Sanchez-Ramos J (1989) Dissociated neurons of the basal forebrain culture. In: A dissection and tissue culture manual of the nervous system (Shahar A, deVellis J, Vernadakis A, Haber B, eds), pp 172-178. New York: Liss.

Hefti F, Junard EO, Knusel B (1991) Promotion of neuronal survival in vitro by thermal proteins and poly(dicarboxylic) amino acids. Brain Res $541: 273-283$

Holtzman DM, Yiwen L, Parada LF, Kinsman S, Chen C, Valletta JS Zhou J, Long JB, Mobley WC (1992) P140 ${ }^{\text {rk }}$ mRNA marks NGFresponsive forebrain neurons: evidence that $t / k$ gene expression is induced by NGF. Neuron 9:465-478.

Honegger $P$ (1985) Biochemical differentiation in serum-free aggregating cell cultures. In: Cell culture in the neurosciences (Nottenstein JE, Sato G, eds), pp 223-243. New York: Plenum.

Johnson EM, Gorin PD, Pearson J (1980) Dorsal root ganglion neurons are destroyed by exposure in utero to maternal antibody to nerve growth factor. Science 210:916-918.

Kaplan FS, Brighton CT, Boytim MJ, Selzer ME, Lee V, Spindler K, Silberberg D, Black J (1986) Enhanced survival of rat neonatal cerebral cortical neurons at subatmospheric oxygen tensions in vitro. Brain Res 384:199-203.

Kew JNC, Svendsen CN, Stevens SJ, Sofroniew MV (1992) CNTF prevents cell death and maintains p7 $5^{\mathrm{NGFR}}$ but not ChAT immunoreactivity in developing septal cholinergic neurons following NGF withdrawal in vitro. Soc Neurosci Abstr 18:617. 
Knusel B, Burton LE, Longo FM, Mobley WC, Koliatsos VE, Price DL, Hefti $F$ (1990) Trophic actions of recombinant human nerve growth factor on cultured rat embryonic CNS cells. Exp Neurol 110:274283

Koh S, Loy R (1989) Localization and development of nerve growth factor-sensitive rat basal forebrain neurons and their afferent projections to hippocampus and neocortex. J Neurosci 9:2999-3018.

Kromer LF (1987) Nerve growth factor treatment after brain injury prevents neuronal death. Science 235:216-218.

Kushima Y, Tsukui H, Enokido Y, Nishio C, Hatanaka H (1990) High oxygen atmosphere for neuronal cell culture with nerve growth factor. I. Primary culture of basal forebrain cholinergic neurons from fetal and postnatal rats. Brain Res 536:16-23.

Lams BE, Isacson O, Sofroniew MV (1988) Loss of transmitter-associated enzyme staining following axotomy does not indicate death of brainstem cholinergic neurons. Brain Res 475:401-406.

Levi-Montalcini R, Angeletti PU (1963) Essentiality of nerve growth factor in the survival and maintenance of dissociated sensory and sympathetic embryonic nerve cells in vitro. Dev Biol 7:653-659.

Lindsay RM (1979) Adult rat brain astrocytes support survival of both NGF-dependent and NGF-insensitive neurons. Nature 282:80-82.

Martin DP, Schmidt RE, DiStefano PS, Lowry OH, Carter JG, Johnson EM Jr (1988) Inhibitors of protein synthesis and RNA synthesis prevent neuronal death caused by nerve growth factor deprivation. J Cell Biol 106:829-844.

McConkey DI, Hartzell P, Duddy SK, Hadansson H, Orrenius S (1988) $1,2,7,8$-Tetrachlorodibenzo-p-dioxin kills immature thymocytes by calcium mediated endonuclease activation. Science 242:256-259.

Mobley WC, Rutkowski JL, Tennekoon GI, Gemski J, Buchanan K, Johnston MV (1986) Nerve growth factor increases choline acetyltransferase activity in developing basal forebrain neurons. Mol Brain Res 1:53-62.

Mufson EJ, Bothwell M, Hersh LB, Kordower JH (1989) Nerve growth factor receptor immunoreactive profiles in the normal, aged human basal forebrain: colocalization with cholinergic neurons. J Comp Neurol 285:196-217.

Oppenheim RW (1989) The neurotrophic theory and naturally occurring motoneuron death. Trends Neurosci 12:252-256.

Oppenheim RW, Prevette D, Tytell M, Shunsaku H (1990) Naturally occurring and induced neuronal death in the chick embryo in vivo requires protein and RNA synthesis: evidence for the role of cell death genes. Dev Biol 138:104-113.

Purves D, Lichtman JW (1985) Principles of neural development, pp 131-153. New York: Sinauer.
Rohrer H, Hofer M, Hellwcg R, Korsching S, Stehle AD, Saadat S, Thoenen $H$ (1988) Antibodies against mouse nerve growth factor interfere in vivo with the development of avian sensory and sympathetic neurones. Development 103:545-552.

Schwartz JP, Pearson J, Johnson EM (1982) Effects of exposure to anti-NGF on sensory neurons of adult rats and guinea pigs. Brain Res 244:378-380.

Seiler M, Schwab M (1984) Specific retrograde transport of nerve growth factor (NGF) from neocortex to nucleus basalis in the rat. Brain Res 300:33-39.

Sofroniew MV, Pearson RCA, Powell TPS (1987) The cholinergic nuclei of the basal forebrain of the rat: normal structure, development and experimentally induced degeneration. Brain Res 411:310-331.

Sofroniew MV, Galletly NP, Isacson O, Svendsen CN (1990) Survival of adult basal forebrain cholinergic neurons after loss of target ncurons. Science 247:338-342.

Sofroniew MV, Cooper JD, Svendsen CN, Crossman P, Ip NY, Lindsay RM, Zafra F, Lindholm D (1993) Atrophy but not death of adult septal cholinergic neurons after ablation of target capacity to produce mRNAs for NGF, BDNF, and NT3. J Neurosci 13:5263-5276.

Springer JE, Loy R (1985) Intrahippocampal injections of antiserum to nerve growth factor inhibit sympathohippocampal sprouting. Brain Res Bull 15:629-634.

Stephens PE, Cuello AC, Sofroniew MV, Pearson RCA, Tagari P (1985) Effect of unilateral decortication on choline acetyltransferase activity in the nucleus hasalis and other areas of the rat brain. J Neurochem 45:1021-1026.

Taniuchi M, Schweitzer JB, Johnson EM Jr (1986) Nerve growth factor receptor molecules in rat brain. Proc Natl Acad Sci US $\Lambda$ 83:19501954.

Vantini G, Schiavo N, Di Martino A, Polato P, Triban C, Callegaro L, Toffano G, Leon A (1989) Evidence for a physiological role of nerve growth factor in the central nervous system of neonatal rats. Neuron $3: 267-273$.

Wenk GL, Olton DS (1984) Recovery of neocortical ChAT activity following ibotenic acid injection into the nucleus basalis of Meynert in rats. Brain Res 293:184-186.

Williams LR, Varon S, Peterson GM, Wictorin K, Fischer W, Bjorklund A, Gage FH (1986) Continuous infusion of nerve growth factor prevents basal forebrain neuronal death after fimbria-fornix transection. Proc Natl Acad Sci USA 83:9231-9235.

Wyllie AH, Kerr JHR, Currie AR (1980) Cell death: the significance of apoptosis. Int Rev Cytol 68:251-306. 